Revista Chilena
De Pediatría

www.revistachilenadepediatria.cl

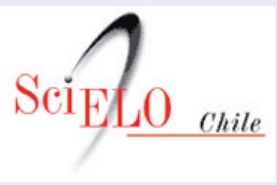

www.scielo.cl

\title{
Adaptación a la realidad de Latinoamérica de la Guía Clínica NASPGHAN/ESPGHAN 2016 sobre Diagnóstico, Prevención y Tratamiento de Infección por Helicobacter pylori en Pediatría
}

\author{
Adaptation to the reality of Latin America of the NASPGHAN/ESPGHAN 2016 \\ Guidelines on the Diagnosis, Prevention and Treatment of Helicobacter pylori \\ Infection in Pediatrics
}

\begin{abstract}
Paul R. Harris ${ }^{a}$, Otto Gerardo Calderón-Guerrero ${ }^{\mathrm{b}}$, José Fernando Vera-Chamorro ${ }^{\mathrm{c}}$, Yalda Lucero ${ }^{\mathrm{d}, \mathrm{e}}$, Margarita Vásquez , Silvio Kazuo Ogata ${ }^{\mathrm{g}}$, Diana Angulo ${ }^{\mathrm{h}}$, Armando Madrazo ${ }^{\mathrm{i}}$, José Gonzáles ${ }^{j}$, Anelsy Rivero ${ }^{\mathrm{k}}$, Juan Cristóbal Gana ${ }^{\mathrm{a}}$, a nombre de la Sociedad Latinoamericana de Gastroenterología, Hepatología y Nutrición Pediátrica (SLAGHNP/LASPGHAN).
\end{abstract}

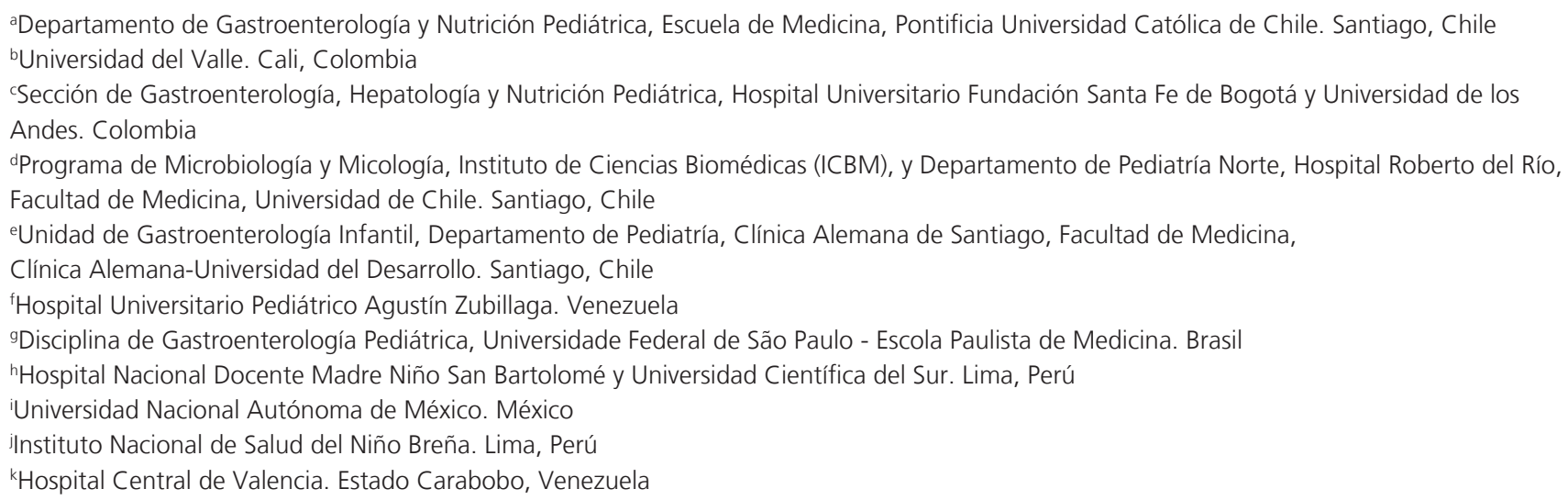

¿Qué se sabe del tema que trata este estudio?

Existen múltiples Guías Clínicas recientes de manejo de la infección por $H$. pylori en medicina de adultos, provenientes de EE. UU., Europa, LA y Asia Pacífico. En pediatría las Guías Clínicas conjuntas de NASPGHAN y ESPGHAN del año 2011, fueron actualizadas el año 2016, pero han surgido cuestionamientos desde LA en cuanto a aplicabilidad de las mismas y en particular con algunas situaciones específicas relacionadas con la prevención de cáncer gástrico.
¿Qué aporta este estudio a lo ya conocido?

La Sociedad Latinoamericana de Gastroenterología, Hepatología y Nutrición Pediátrica (SLAGHNP/LASPGHAN) conformó un grupo de estudio con expertos provenientes de 6 países para analizar las guías vigentes de NASPGHAN/ ESPGHAN 2016 y ofrece un documento de análisis basado en los datos actuales y realidad latinoamericana.

Correspondencia:

Paul R. Harris

pharris@med.puc.cl 


\section{Resumen}

Introducción: Las últimas guías clínicas conjuntas de NASPGHAN y ESPGHAN en relación a la infección por $H$. pylori publicadas el año 2016, contienen 20 afirmaciones que han sido cuestionadas en la práctica respecto a su aplicabilidad en Latinoamérica (LA); en particular en relación a la prevención del cáncer gástrico. Métodos: Se realizó un análisis crítico de la literatura, con especial énfasis en datos de LA y se estableció el nivel de evidencia y nivel de recomendación de las afirmaciones mas controversiales de las Guías Conjuntas. Se realizaron 2 rondas de votación de acuerdo a la técnica Delfi de consenso y se utilizó escala de Likert (de 0 a 4) para establecer el "grado de acuerdo" entre un grupo de expertos de SLAGHNP. Resultados: Existen pocos estudios en relación a diagnóstico, efectividad de tratamiento y susceptibilidad a antibióticos de $H$. pylori en pacientes pediátricos de LA. En base a estos estudios, extrapolaciones de estudios de adultos y la experiencia clínica del panel de expertos participantes, se realizan las siguientes recomendaciones. Recomendamos la toma de biopsias para test rápido de ureasa e histología (y muestras para cultivo o técnicas moleculares, cuando estén disponibles) durante la endoscopia digestiva alta sólo si en caso de confirmar la infección por $H$. pylori, se indicará tratamiento de erradicación. Recomendamos que centros regionales seleccionados realicen estudios de sensibilidad/resistencia antimicrobiana para $H$. pylori y así actúen como centros de referencia para toda LA. En caso de falla de erradicación de H. pylori con tratamiento de primera línea, recomendamos tratamiento empírico con terapia cuádruple con inhibidor de bomba de protones, amoxicilina, metronidazol y bismuto por 14 días. En caso de falla de erradicación con el esquema de segunda línea, se recomienda indicar un tratamiento individualizado considerando la edad del paciente, el esquema indicado previamente y la sensibilidad antibiótica de la cepa, lo que implica realizar una nueva endoscopía con extracción de muestra para cultivo y antibiograma o estudio molecular de resistencia. En niños sintomáticos referidos a endoscopía que tengan antecedente de familiar de primer o segundo grado con cáncer gástrico, se recomienda considerar la búsqueda de H. pylori mediante técnica directa durante la endoscopia (y erradicarlo cuando es detectado). Conclusiones: La evidencia apoya mayoritariamente los conceptos generales de las Guías NASPGHAN/ ESPGHAN 2016, pero es necesario adaptarlas a la realidad de LA, con énfasis en el desarrollo de centros regionales para el estudio de sensibilidad a antibióticos y mejorar la correcta selección del tratamiento de erradicación. En niños sintomáticos con antecedente familiar de primer o segundo grado de cáncer gástrico, se debe considerar la búsqueda y erradicación de H. pylori.

\section{Abstract}

Introduction: The latest joint $H$. pylori NASPGHAN and ESPGHAN clinical guidelines published in 2016, contain 20 statements that have been questioned in practice regarding their applicability in Latin America (LA); in particular in relation to gastric cancer prevention. Methods: We conducted a critical analysis of the literature, with special emphasis on LA data and established the level of evidence and level of recommendation of the most controversial claims in the Joint Guidelines. Two rounds of voting were conducted according to the Delphi consensus technique and a Likert scale (from 0 to 4 ) was used to establish the "degree of agreement" among a panel of SLAGHNP experts. Results: There are few studies regarding diagnosis, treatment effectiveness and susceptibility to antibiotics of $H$. pylori in pediatric patients of LA. Based on these studies, extrapolations from adult studies, and the clinical experience of the participating expert panel, the following recommendations are made. We recommend taking biopsies for rapid urease and histology testing (and samples for culture or molecular techniques, when available) during upper endoscopy only if in case of confirmed $H$. pylori infection, eradication treatment will be indicated. We recommend that selected regional centers conduct antimicrobial sensitivity/resistance studies for $H$. pylori and thus act as reference centers for all LA. In case of failure to eradicate $H$. pylori with first-line treatment, we recommend empirical treatment with quadruple therapy with proton pump inhibitor, amoxicillin, metronidazole, and bismuth for 14 days. In case of eradication failure with the second line scheme, it is recommended to indicate an individualized treatment considering the age of the patient, the previously indicated scheme and the antibiotic sensitivity of the strain, which implies performing a new endoscopy with sample extraction for culture and antibiogram or molecular resistance study. In symptomatic children referred to endoscopy who have a history of first or second degree family members with gastric cancer, it is recommended to consider the search for $H$. pylori by direct technique during endoscopy (and eradicate it when detected). Conclusions: The
Palabras clave:

H. pylori;

Test Rápido de Ureasa;

Latinoamérica;

Test de Urea en Aire

Espirado C13;

Test de Antígeno Fecal;

Cáncer Gástrico

\section{Keywords:}

H. pylori;

Rapid Urease Test;

Latin America;

C13 Urea Breath Test;

Fecal Antigen Test;

Gastric Cancer 
evidence supports most of the general concepts of the NASPGHAN/ESPGHAN 2016 Guidelines, but it is necessary to adapt them to the reality of LA, with emphasis on the development of regional centers for the study of antibiotic sensitivity and to improve the correct selection of the eradication treatment. In symptomatic children with a family history of first or second degree gastric cancer, the search for and eradication of $H$. pylori should be considered.

\begin{tabular}{|c|c|}
\hline \multicolumn{2}{|l|}{ Abreviaciones } \\
\hline Helicobacter pylori & H. pylori \\
\hline Test Rápido de Ureasa & RUT* \\
\hline Endoscopia Digestiva Alta & EDA \\
\hline Desórdenes gastrointestinales funcionales & FGIDs* \\
\hline Latino América & LA \\
\hline Dolor Abdominal Funcional & FAPD* \\
\hline Test de Urea en Aire Espirado C13 & UBT-C 13* \\
\hline Test de Antígeno Fecal & HpSAg* \\
\hline Inhibidores de Bomba de Protones & IBP \\
\hline Cáncer Gástrico & $C G$ \\
\hline Ulcera Gástrica & UG \\
\hline Úlcera Duodenal & UD \\
\hline Ulcera gastroduodenal & UGD \\
\hline Gastropatía Nodular & GN \\
\hline Reacción de Polimerasa en Cadena & $P C R^{*}$ \\
\hline Claritromicina & CLA \\
\hline Metronidazol & MET \\
\hline Amoxicilina & AMO \\
\hline *en inglés por ser siglas internacionales & \\
\hline
\end{tabular}

\section{Introducción}

La infección por Helicobacter pylori (H. pylori) en Latinoamérica (LA) continúa siendo un problema relevante por su prevalencia y el impacto médico y social de sus patologías asociadas ${ }^{1}$. El estudio de esta infección en LA ha estado liderado por especialistas de adultos y con un enfoque predominantemente dirigido a las secuelas que produce la infección y particularmente a la prevención de cáncer gástrico (CG), pero escasamente abordan temas propios de la población infantil.

Existen múltiples Guías Clínicas recientes en medicina de adulto provenientes de EE. UU., Europa, LA y Asia Pacífico ${ }^{2-7}$. En pediatría los primeros intentos fueron liderados por el grupo canadiense de estudio de H. pylori ${ }^{8}$ y posteriormente por las Guías Clínicas conjuntas de NASPGHAN y ESPGHAN del año 2011, las cuales fueron actualizadas el año $2016^{\circ}$. Con la publicación de las 20 afirmaciones de dichas guías (tabla 1), han surgido cuestionamientos desde LA en cuanto a aplicabilidad de las mismas y en particular con algunas situaciones especificas relacionadas con la prevención de CG.

Por lo tanto, la Sociedad Latinoamericana de Gastroenterología, Hepatología y Nutrición Pediátrica (SLAGHNP/LASPGHAN) ha conformado un grupo de estudio con expertos provenientes de 6 países (Brasil, Chile, Colombia, México, Perú y Venezuela) para analizar las guías vigentes y actuales de NASPGHAN/ ESPGHAN 2016 (publicadas 2017) y ofrecer un documento de análisis basado en los datos actuales y realidad lationamericana.

\section{Metodología}

\section{Primera etapa}

A partir de las 20 afirmaciones contenidas en las Guías NASPGHAN/ESPGHAN 2016 se definieron aquellas que eran factibles de evaluar/reconsiderar a nivel latinoamericano (tabla 1). Cada miembro del panel (Grupo de Estudio) identificó afirmaciones en forma individual para luego seleccionar por consenso las que deberían ser evaluadas para LA. De esta forma se identificaron de manera consensuada las afirmaciones de interés en relación a diagnóstico, prevención y tratamiento de la infección por $H$. pylori en pediatría, siguiendo metodología Delfi ${ }^{10}$, con un panel de 10 expertos más un asesor metodológico. Resultaron afirmaciones altamente controversiales las $2 \mathrm{a}, 4,9 \mathrm{a}, 9 \mathrm{~b}$ y 14; afirmaciones moderadamente controversiales las 2b, 11, 12, 15 y 16; y afirmaciones minimamente o no controversiales las 1, 2c, 3, 5a, 5b, 6, 7, 8, 10 y 13 .

\section{Segunda Etapa}

Una vez seleccionadas las afirmaciones a evaluar, se realizó un análisis crítico de la literatura, con especial énfasis en datos de LA y se estableció el nivel de evidencia y nivel de recomendación del enunciado. Se asignó uno o dos responsables para cada afirmación, los cuáles fueron encargados de presentar al panel en formato estándar (descrito más abajo).

\section{Niveles de evidencia y niveles de recomendación}

La evaluación de la calidad de la evidencia que sustenta cada afirmación se realizó en forma descriptiva, fundamentándose en el tipo de diseño de los estudios, adaptado de las recomendaciones realizadas por la U.S. 
Tabla 1. Resumen Recomendaciones NASPGHAN/ESPGHAN* y nivel de controversia para LA de acuerdo a consenso de panel de expertos SLAPGHN

\begin{tabular}{cl}
\hline$N^{\circ}$ & Recomendación \\
\hline 1 & $\begin{array}{l}\text { Recomendamos que el objetivo primario en la investigación de síntomas gastrointestinales debe- } \\
\text { ría ser la determinación de la causa subyacente de los síntomas y no únicamente la presencia de } \\
\text { infección por } H . \text { pylori }\end{array}$ \\
$2 \mathrm{2a}$ & $\begin{array}{l}\text { Recomendamos que durante una endoscopia la toma de biopsias adicionales para RUT y cultivo } \\
\text { solo debieran tomarse si es probable que se ofrezca tratamiento en caso de confirmarse la infección }\end{array}$ \\
$2 \mathrm{~b} \quad \begin{array}{l}\text { Sugerimos que si la infección por } \mathrm{H} \text {. pylori es un hallazgo incidental en endoscopia, el tratamiento } \\
\text { podría ser considerado después de una cuidadosa discusión de los riesgos y beneficios del trata- } \\
\text { miento para } H \text {. pylori con el paciente y sus padres }\end{array}$
\end{tabular}

2c Recomendamos en contra de una estrategia de "testear y tratar" para la infección por H. pylori en niños

3 Recomendamos que la búsqueda de $H$. pylori debe ser realizada en niños con ulcera gástrica o duodenal. Si el $H$. pylori es identificado entonces se debe tratar y confirmar su erradicación

4 Recomendamos en contra de búsqueda en $\mathrm{H}$. pylori en niños con dolor abdominal funcional

5a Recomendamos en contra de búsqueda en $H$. pylori como parte de la evaluación inicial en niños con anemia por deficiencia de hierro

5b Sugerimos que en niños con anemia refractaria por deficiencia de hierro en que se han descartado otras causas, una endoscopia con búsqueda de $H$. pylori sea considerada

6 Sugerimos considerar búsqueda de $H$. pylori por métodos no invasivos cuando se esté evaluando causas de purpura trombocitopénico crónico inmune

7 Recomendamos en contra de la búsqueda de $H$. pylori en el estudio de niños con talla baja

8 Recomendamos que antes de buscar infección por $H$. pylori, esperar al menos 2 semanas después de completar el uso de inhibidores de bomba de protones y 4 semanas después de antibióticos

9a Recomendamos que el diagnostico de H. pylori debería estar basado en (a) histología (gastritis con H. pylori) más al menos 1 test basado en biopsia, o (b) cultivo positivo

9b Recomendamos que para el diagnóstico de infección por H. pylori en una EDA, al menos 6 biopsias gástricas sean obtenidas

10 Recomendamos en contra de usar test basados en anticuerpos ( $\lg G, \lg A)$ anti-H. pylori en suero, sangre, orina y saliva en el manejo clínico rutinario

11 Recomendamos que la sensibilidad antimicrobiana sea obtenida para la cepa infectante de $H$. pylori y que la terapia de erradicación sea diseñada en concordancia

12 Recomendamos que la efectividad de la terapia de primera línea sea evaluada en centros nacionales/regionales

13 Recomendamos que el médico explique al paciente/familia la importancia de adherir a la terapia anti-H. pylori para aumentar la erradicación exitosa

14 Recomendamos la terapia de primera línea para la infección por $H$. pylori según la tabla 2

15 Recomendamos que la evaluación de la terapia anti-H. pylori sea evaluada al menos 4 semanas después de completar el tratamiento usando uno de los siguientes exámenes: (a) UBT-C13 o (b) HpSAG monoclonal

16 Recomendamos que cuando el tratamiento anti-H. pylori fracasa, la terapia de rescate debe ser individualizada considerando la susceptibilidad antibiótica, la edad del niño, y las opciones antimicrobianas disponibles
Nivel de controversia para LA

Sin mayor controversia

Altamente controversial

Moderadamente controversial

Sin mayor controversia

Sin mayor controversia

Altamente controversial

Sin mayor controversia

Sin mayor controversia

Sin mayor controversia

Sin mayor controversia

Sin mayor controversia

Altamente controversial

Altamente controversial

Sin mayor controversia

Moderadamente controversial

Moderadamente controversial

Sin mayor controversia

Altamente controversial

Moderadamente controversial

Moderadamente controversial 
Preventive Services Task Force ${ }^{11,12}$. La estratificación de la evidencia se realizó según el diseño de cada estudio (tabla 2). Cada estrato representa un nivel de calidad. Cada nivel está ordenado en forma decreciente, así, los estudios clínicos controlados aleatorizados y las revisiones sistemáticas de estudios clínicos aleatorizados corresponden a la evidencia de mayor calidad; los estudios clínicos observacionales corresponden a un nivel de evidencia intermedio; los estudios fisiopatológicos y la opinión de expertos corresponden al estrato de menor calidad. Para cada pregunta se recomendó describir los estudios más relevantes en términos de diseño y sus resultados (con sus respectivos intervalos de confianza y/o valor $p$ ). El nivel de recomendación se estableció de acuerdo a la tabla 3.

Se solicitó a cada experto que revisara la afirmación asignada utilizando como base las referencias en búsqueda estructurada en MEDLINE y SCIELO. En base a la información recopilada el experto debió revisar cada afirmación o sub-afirmación (ya que algunas de ellas están subdivididas) sin límite en el número de referencias. La respuesta debió fundamentarse en la mejor evidencia disponible en la literatura y debía culminar en una recomendación breve, concisa y atingente, a la que debía asignarse un "nivel de evidencia" y un "nivel de recomendación" (de acuerdo a los criterios previamente descritos).

\section{Tercera Etapa}

Se realizó una primera ronda de votación donde, de acuerdo a la técnica Delfi de consenso, los coordinadores encargados del proyecto recibieron la información enviada por cada experto y se generó un documento que incluyó cada una de las respuestas a las afirmaciones. Los niveles de evidencia y de recomendación fueron revisados de manera centralizada para uniformar criterios y el documento fue re-enviado a los expertos, quienes debieron votar y dar su opinión respecto a todas las afirmaciones en el sitio señalado como "grado de acuerdo" y utilizando una escala Likert de 0 a 4 (0: Completamente en desacuerdo; 1: En desacuerdo; 2: Dudoso o con reparos; 3: De acuerdo; 4: Completamente de acuerdo). En caso de votar 0,1 o 2, cada experto debió insertar un texto breve explicando sus razones o colocar un nuevo ejemplo de enunciado.

\section{Tabla 2. Nivel de la evidencia*}

\begin{tabular}{cl}
\hline Nivel de evidencia & Descripción \\
\hline Tipo I & $\begin{array}{l}\text { Evidencia obtenida de al menos un estudio controlado }{ }^{1} \text { aleatorizado bien diseñado o una revisión sistemática de estudios } \\
\text { clínicos aleatorizados }\end{array}$ \\
Tipo II & I-1 Evidencia obtenida de estudios controlados ${ }^{1}$ prospectivos no aleatorizados \\
& II-2 Evidencia obtenida de estudios observacionales ${ }^{2}$ de tipo cohorte o casos y controles, idealmente de varios centros \\
& O-3 Evidencia obtenida de series de casos \\
Tipo III & Opinión de autoridades en el tema basados en la experiencia, comités de expertos, reporte de casos, estudios fisiopato- \\
& lógia básica
\end{tabular}

'Se entiende como estudio controlado a aquel en que la intervención es manejada por el investigador. ${ }^{2}$ Se entiende como estudio observacional a aquel en que la intervención no es controlada por el investigador. *Adaptado de Referencias 10-12.

\section{Tabla 3. Nivel de Recomendación*}

\begin{tabular}{cl}
\hline Recomendación & Lenguaje \\
\hline A & $\begin{array}{l}\text { El consenso recomienda fuertemente la intervención o servicio indicado. Esta recomendación se sustenta en evidencia } \\
\text { de alta calidad, con beneficio categórico que supera los riesgos }\end{array}$ \\
B & $\begin{array}{l}\text { El consenso recomienda el uso clínico rutinario de la intervención o servicio indicado. La recomendación se sustenta en } \\
\text { evidencia de calidad moderada, con beneficio que supera los riesgos }\end{array}$ \\
Cl consenso no recomienda ni a favor ni en contra de la intervención o servicio. No se realiza una recomendación cate- \\
górica dado que la evidencia, de calidad al menos moderada, no muestra una relación riesgo/beneficio satisfactoria. Se \\
debe decidir caso a caso \\
El consenso recomienda en contra de la intervención o servicio. La recomendación se sustenta en evidencia de calidad al \\
menos moderada que no muestra beneficio o que el riesgo o daño supera los beneficios de la intervención \\
El consenso concluye que la evidencia es insuficiente, ya sea por estudios de baja calidad, resultados heterogéneos, o el \\
balance riesgo/beneficio no puede ser determinado
\end{tabular}

*Adaptado de Referencias 10-12. 
Se analizó la información obtenida de la primera ronda y se preparó el documento con las respuestas del panel de expertos a cada una de las afirmaciones y se les solicitó hacer los cambios requeridos de acuerdo a las opiniones respecto a la pregunta que les correspondió analizar.

\section{Cuarta Etapa}

Se realizó una segunda ronda de votación, utilizando la metodología descrita en la primera ronda. Finalmente se realizó la integración de la información post segunda ronda de votación lo cual constituyó el fundamento de esta publicación.

\section{Manuscrito final}

El manuscrito final fue evaluado y aprobado por cada uno de los expertos que conformaron el Grupo de Estudio. Este documento fue revisado y aprobado por la Directiva de SLAGHNP.

\section{Recomendaciones}

Las siguientes recomendaciones de SLAGHNP hacen referencia a las afirmaciones originales publicadas por NASPGHAN/ESPGHAN ${ }^{9}$ y usan el mismo número correlativo para facilitar su identificación (tabla 1).

\section{Sobre la indicación de tomar biopsias para identificar la presencia de $H$. pylori en niños sometidos a endoscopía digestiva alta (Recomendaciones 2a y $2 b$ )}

\section{Puntos Prácticos:}

a. Durante una endoscopía digestiva alta (EDA) de un paciente que tenga alguna condición que justifique dar terapia de erradicación, se deben tomar biopsias para estudio histológico y Test Rápido de Ureasa (RUT, sigla en inglés), para confirmar diagnóstico. La toma de una biopsia adicional para estudio de resistencia/sensibilidad a antibióticos será tratado en extenso mas adelante.

b. De acuerdo a la evidencia actual, solo está justificada la toma de muestra y erradicación en caso de erosiones o úlceras gástrica o duodenal (UGD) o antecedente familiar de CG. La presencia de gastropatía nodular (GN) es aun tema de debate y será tratado en extenso mas adelante.

c. Sobre ofrecer tratamiento para erradicar H. pylori en niños sin las lesiones antes descritas, el médico debe explicar que la infección por $H$. pylori no es la causa de los síntomas y que probablemente después del tratamiento no se debería esperar la desaparición de los síntomas. Además se debe discutir con los padres y niños mayores el potencial riesgo de desarrollar complicaciones relacionadas con la infección (UGD, CG) en edades tardías y se debe explicar los riesgos del tratamiento incluyendo falla del mismo, efectos adversos por los antibióticos como diarrea, reacciones alérgicas, alteraciones del microbioma intestinal, entre otros.

\section{Comentarios}

En general, en ausencia de lesiones pépticas, el diagnóstico de la infección por métodos dependientes de biopsia endoscópica con el solo propósito de identificar la infección por H. pylori no es apropiado. Sin embargo, la infección por $H$. pylori puede ser encontrada en forma incidental cuando la EDA es realizada para diagnosticar otras patologías como Enfermedad Inflamatoria Intestinal o Enfermedad Celiaca, en especial en áreas de alta prevalencia de esta infección. En LA donde la posibilidad de realizar EDA no es del todo fácil, en ciertas zonas y poblaciones, es primordial basarse en los hallazgos clínicos.

Erradicar $H$. pylori en niños sólo se justifica si el beneficio es mayor que el riesgo y costo del tratamiento, especialmente considerando que el tratamiento no elimina los síntomas, a excepción de la UGD ${ }^{13}$. En un estudio de infección por $H$. pylori asociada a gastritis histológica sin lesiones erosivas, en la mucosa gástrica o duodenal se observó que raramente ésta lleva a progresión de la enfermedad o complicación de la misma durante la infancia ${ }^{13}$. Esto puede ser explicado por la diferente respuesta inmune a la infección. En comparación con los adultos, los niños infectados presentan una respuesta inmune mucosal con mayor participación de células T regulatorias y su efecto antiinflamatorio $^{14,15}$. Adicionalmente, la tasa de reinfección por $H$. pylori luego de la erradicación parece ser bastante alta en $\mathrm{LA}^{16}$. Un estudio en Bolivia en ciudades de alta prevalencia y poblaciones de bajos recursos, observó una tasa de reinfección de $20 \%$ un año después de la erradicación en niños menores de 10 años ${ }^{17}$. Finalmente, el riesgo de CG o linfoma MALT asociado a infección por H. pylori durante la infancia es extremadamente bajo en Europa y Norte América y probablemente también en LA en ausencia de historia familiar de CG (este aspecto se discutirá en extenso mas adelante).

Un aspecto en pleno estudio es la relación inversa entre infección por $H$. pylori y enfermedades alérgicas, donde habría un potencial rol beneficioso de la infección en la infancia temprana, que sería un argumento adicional para evitar la erradicación injustificada de la bacteria $^{18}$.

Recomendación 2a SLAGHNP: Recomendamos la toma de biopsia para RUT e histología (y biopsias para cultivo o técnicas moleculares, cuando esté disponible) durante la endoscopia digestiva alta, sólo si 
se administrará tratamiento en caso de confirmar la infección.

Nivel de evidencia: $\quad$ II-2

Nivel de recomendación: $\quad$ B

Grado de acuerdo PROMEDIO: $\quad 3,4$

Recomendación 2b SLAGHNP: Recomendamos que si la infección por $H$. pylori es un hallazgo fortuito en la endoscopia, el tratamiento puede ser considerado con una detallada discusión del mismo con el paciente y sus padres.

Nivel de evidencia:

III

Nivel de recomendación:

C

Grado de acuerdo PROMEDIO: $\quad 3,4$

\section{Sobre la indicación de erradicación frente al hallazgo de $H$. pylori en niños asintomáticos o con síntomas digestivos funcionales (Recomendación 4)}

\section{Puntos Prácticos}

a. Roma IV ha establecido que los desórdenes gastrointestinales funcionales de niños y adolescentes (FGIDs, sigla en inglés) no constituyen simplemente la ausencia de enfermedad orgánica. Debemos considerar diagnosticar algún FGIDs si después de una adecuada evaluación clínica médica los síntomas, finalmente, no puedan ser atribuidos a ninguna condición médica de origen orgánico ${ }^{19}$. Un diagnóstico positivo de FGIDs puede requerir alguna prueba diagnóstica muy puntual (o ninguna) y debe cumplir un conjunto de criterios clínicos de inclusión de síntomas que Roma IV los ha propuesto y ya están definidos en publicaciones ${ }^{20}$. Siempre existirá la posibilidad de la coexistencia de FGIDs y alguna condición orgánica de enfermedad.

Al definirse en forma más rigurosa los criterios de inclusión, se establece mejor el requerimiento diagnóstico de los diferentes tipos de Dolor Abdominal Funcional (FAPD, sigla en inglés). Es posible establecer entonces un listado de preguntas y generar encuestas aplicables a diferentes poblaciones de niños y adolescentes de diversos países del mundo ${ }^{21}$. Algunos estudios recientes en LA que han empleado los criterios diagnósticos de Roma III sugieren que la prevalencia de FAPD en diferentes ciudades, de variada condición económica y de poblaciones diferentes, es comparable con la de países más desarrollados ${ }^{22-24}$.

b. La infección por H. pylori en niños y adolescentes puede expresarse mediante manifestaciones digestivas y extra digestivas o puede ser, con más frecuencia, silente ${ }^{25}$. En LA, la prevalencia de infección, en la población general, es elevada, pu- diendo presentarse primo infección desde edades tempranas, y tiene, al parecer, una historia natural algo diferente a aquella evaluada en niños de países más desarrollados ${ }^{26} \mathrm{y}$ deben ser considerados al momento de evaluar la posibilidad de diagnosticar y erradicar la bacteria. Estudios de seguimiento de niños infectados por $H$. pylori en LA, diagnosticados mediante diferentes procedimientos, tanto en medios rurales como urbanos, establecen alta tasa de recurrencia anual de infección en nuestra población ${ }^{27}$. En México la reinfección o recurrencia es $11,7 \%$ a $18 \%$, situación que se asocia a bajo nivel socioeconómico ${ }^{28}$. La reaparición de la bacteria en Perú después del tratamiento se debe $80 \%$ a reinfección y $20 \%$ a recurrencia, según las pruebas de tipificación bacteriana del DNA. Las tasas de reinfección en Lima en los últimos años han disminuido de $70 \%$ a $30 \%$ en los pacientes de nivel socioeconómico bajo $^{27}$. Una alta prevalencia de la infección ha presionado a un uso indiscriminado de antibióticos con presencia creciente de resistencia a antimicrobianos ${ }^{29}$.

\section{Comentarios}

La presencia de dolor abdominal en niños y adolescentes localizado en la parte alta del abdomen es motivo frecuente de consulta. La intensidad del dolor puede ser variada. La coexistencia de pacientes con dolor abdominal y comportamiento clínico de FAPD y la existencia en nuestro medio de una alta prevalencia de infección por $H$. pylori abre el razonable cuestionamiento sobre causalidad o simple coexistencia. Jaime y cols. ${ }^{30}$ en un estudio transversal, con 358 niños, no encontraron diferencia en ninguna variante de FGIDs en niños infectados comparados con no infectados, sin embargo, en el análisis multivariado, la presencia de dolor abdominal aislado se relacionó a la infección por $H$. pylori (OR 1,55; 95\% CI [1,02, $2,36]$ ).

Desconocemos si en nuestro medio, en donde se presenta una alta tasa de infección recurrente, estos episodios de reinfección tienen expresividad clínica o es, como pudiera suponerse, la mayoría de veces silente. En una población como la de LA, con alta tasa de reinfección, la presencia de episodios sintomáticos de dolor pudiera coexistir o exacerbar los síntomas de un eventual paciente con diagnóstico de FAPD ${ }^{31-32}$.

La gastropatía nodular (GN) es más frecuente en la niñez y adolescencia comparada con la población de adultos. No fue descrita en los reportes originales de patología gástrica asociada a infección por H. pylori por el grupo de Sidney ${ }^{33}$. Recientemente se ha reportado que la GN por $H$. pylori es un hallazgo más común en la población infantil ( $44 \%-67 \%$ en niños vs $0,19 \%$ $13 \%$ en adultos $)^{34,35}$. Constituye un hallazgo endos- 
cópico y se ha relacionado su presencia a una mayor densidad microbiana ${ }^{36}$. No existen estudios de seguimiento prolongados y desconocemos si la GN genera síntomas de dolor o si su presencia establece alguna condición de riesgo en particular, o si solo sugiere una intensa reactividad inmune y se desconoce si expone a riesgos futuros ${ }^{37}$. En un estudio de LA en 48 adultos en Chile, la GN no se asoció con lesiones preneoplasicas, pero si se asoció con un aumento en la carga bacteriana sin un aumento concomitante en la respuesta inflamatoria mucosal ${ }^{38}$. En otro estudio de 172 casos y 172 controles en adultos en Colombia, los casos tenían más frecuentemente lesiones gástricas premalignas (OLGA II; 6,5 vs 1,2\%, p = 0,01). En ese estudio no se demostró la asociación de GN con cáncer gástrico, sin embargo, hubo un caso de una lesión neoplásica en el grupo de $\mathrm{GN}^{39}$. La indicación de erradicación en un niño infectado con GN es aun tema de debate y debe ser considerado en forma individual.

En conclusión, la presencia de FAPD ahora está claramente definida en términos diagnósticos gracias a Roma IV, sin embargo, no se puede excluir la posible asociación simultánea con gastritis crónica por $H$. pylori. En poblaciones de alta prevalencia de infección por H. pylori aún falta identificar qué grupos de niños y bajo qué factores de riesgo evolucionan a condiciones de mayor severidad de compromiso de la mucosa gástrica como pudiera ser la presencia de úlcera (baja prevalencia en población pediátrica).

Fuera de las condiciones identificadas como signos de alarma reconocidas por el consenso NASPGHAN/ ESPGHAN ${ }^{9}$, la más importante característica a discutir al tomar la decisión de realizar una EDA cuando hay dolor abdominal es la severidad de dolor epigástrico reportada por el paciente o la familia. Es posible considerar la recomendación de realizar una EDA si el dolor epigástrico es intenso, se asocia a baja de peso, o despierta en la noche al niño.

Recomendación 4 SLAGHNP: En niños con dolor abdominal funcional, en ausencia de señales de alarma, se desaconseja la realización de test para búsqueda de H. pylori. En niños con dispepsia o dolor abdominal con señales de alarma de acuerdo a los criterios Roma IV, se recomienda como primera opción realizar endoscopia digestiva alta, para determinar la presencia de lesiones y otras causas de dolor abdominal. En caso de identificar alguna lesión (úlcera, erosiones), se recomienda tomar biopsias para RUT e histología y de estar disponible, también biopsias para cultivo o tecnicas moleculares. En caso de identificar H. pylori, debe considerarse tratamiento de erradicación.

Nivel de evidencia: III

Nivel de recomendación: B

Grado de acuerdo PROMEDIO: $\quad$ 2,4
Sobre las técnicas disponibles para diagnosticar la infección por H. pylori (Recomendaciones 9a y 9b)

\section{Puntos Prácticos:}

a. Para investigar la "enfermedad" asociada a H. pylori en niños, debe realizarse una EDA con biopsias para histología, RUT e idealmente cultivo, y no debe basarse en pruebas no invasivas como Test de Urea en Aire Espirado C13 (UBT-C13, sigla en inglés), Test de Antígeno Fecal (HpSAg, sigla en inglés) u otros métodos no invasivos.

b. El diagnóstico histopatológico de gastritis por $H$. pylori debe realizarse utilizando la clasificación de Sydney actualizada ${ }^{40}$. Al menos 5 biopsias gástricas deben tomarse en una EDA para detectar la infección por $H$. pylori. Dos biopsias de antro y dos biopsias del cuerpo para evaluación histopatológica aplicando clasificación de Sydney actualizada ${ }^{40}$, y una biopsia de antro para RUT.

c. Si están disponibles, se debe tomar al menos 1 biopsia del antro y 1 de cuerpo para el cultivo y una biopsia de antro para pruebas moleculares como Reacción de Polimerasa en Cadena (PCR, sigla en inglés) o hibridación fluorescente in situ ${ }^{41-42}$ para estudio de sensibilidad antimicrobiana pero no para fines diagnósticos clínicos. En LA se realiza cultivo y/o PCR con fines de investigación en varios países: Argentina, Brasil, Chile, Colombia, Costa Rica, Cuba, Ecuador, México, Paraguay, Perú, Uruguay y Venezuela ${ }^{43}$. En algunas ciudades de Colombia y Chile se realiza cultivo para estudio de sensibilidad antimicrobiana de H. pylori con fines clínicos ${ }^{44-45}$.

d. Las biopsias tomadas durante un episodio de hemorragia digestiva pueden dar resultados falsos negativos para histología, cultivo, RUT o pruebas moleculares ${ }^{41-42}$.

e. Las biopsias para cultivo y pruebas moleculares deben ser colocadas en medios especiales, refrigeradas si es necesario y transportadas a la mayor brevedad posible, al centro de procesamiento para mejorar su rendimiento.

\section{Comentarios}

El objetivo de la investigación invasiva basada en EDA y biopsias es detectar la causa de los síntomas y no sólo la presencia de $H$. pylori, dado que la evidencia en niños indica que la infección por $H$. pylori no se asocia con síntomas en ausencia de $\mathrm{UGD}^{46}$. Ninguna de las pruebas diagnósticas disponibles tiene una sensibilidad y especificidad del 100\%. Según un informe del NIHR (National Institute for Health Research) de 2017, la sensibilidad y especificidad para la histología es del 66\%-86\% y > 98\%, respectivamente. Actualmente se ha mejorado la detección de infección por 
H. pylori en histología, adicionándole pruebas de inmunohistoquímica (anticuerpos anti- $H$. pylori marcados), con sensibilidad y especificidad $>97 \%$ y $100 \%$, respectivamente ${ }^{47,48}$.

La sensibilidad y especificidad para RUT es $80-95 \%$ y $97-99 \%$, respectivamente ${ }^{48}$. El RUT según algunos estudios, requiere un mínimo de dos biopsias gástricas (cuerpo y antro) y una carga bacteriana alta para garantizar una precisión óptima. Sin embargo, el valor predictivo positivo de las pruebas aumenta, si la prevalencia de la infección es alta como sucede en los países de $\mathrm{LA}^{49}$, por lo que, en general una sola prueba positiva es suficiente. Para una adecuada interpretación del RUT se debe considerar que la sensibilidad es menor en menores de 4 años y aumenta con la edad y con el mayor número de biopsias, esto debido a la baja densidad bacteriana en niños pequeños, comparada con adolescentes y adultos ${ }^{50}$.

La sensibilidad y especificidad del cultivo es $60 \%$ y $100 \%$, respectivamente ${ }^{9,44,48,51}$. Las pruebas moleculares dependientes de biopsia (PCR o hibridación fluorescente in situ) serán discutidas en una sección mas adelante.

Recomendación 9a SLAGHNP: El diagnóstico de infección por $H$. pylori debe realizarse en pacientes sintomáticos basado en biopsias obtenidas por medio de EDA, con al menos dos de las siguientes pruebas positivas: RUT, histología, o cultivo.

Nivel de evidencia: I

Grado de recomendación: A

Grado de acuerdo PROMEDIO: 4

Recomendación 9b SLAGHNP: Se deben tomar al menos 5 biopsias gástricas para el diagnóstico de infección por $H$. pylori en la EDA. Deben obtenerse dos biopsias del antro y dos biopsias del cuerpo para la evaluación histopatológica aplicando la clasificación Sydney y una biopsia de antro para RUT; idealmente podrían tomarse biopsias adicionales si existen técnicas para estudio de sensibilidad antimicrobiana (cultivo o técnicas moleculares).

Nivel de evidencia: III

Grado de recomendación: A

Grado de acuerdo PROMEDIO: $\quad 3,6$

Sobre el estudio de susceptibilidad a antimicrobianos de H. pylori (Recomendación 11)

\section{Puntos prácticos}

a. A pesar de la reconocida importancia de las pruebas de susceptibilidad antimicrobiana de $H$. pylori tanto para el patrón de resistencia antimicrobiana regional como para la personalización del tratamiento de erradicación, al menos en LA, no existe un sistema de vigilancia y en general no se realiza de manera rutinaria. b. Los métodos de susceptibilidad antimicrobiana basados en estudios moleculares y en cultivo están disponibles sólo en grandes ciudades y como estudios de investigación, generalmente no como pruebas de laboratorio de rutina.

c. Los antimicrobianos disponibles para la prescripción pediátrica son limitados.

\section{Comentarios}

Lo ideal es que se realicen pruebas de susceptibilidad a todos y a cada uno de los pacientes infectados por H. pylori, y el tratamiento de erradicación debe ser personalizado para cada paciente. La superioridad del tratamiento guiado por los exámenes de susceptibilidad en lugar del tratamiento antimicrobiano de primera línea empírico es bien conocida, así como para el tratamiento de rescate ${ }^{52,53}$. Los beneficios de una erradicación exitosa (cuando ello está indicado) son bien conocidos, evitando el desarrollo de enfermedades graves asociadas a infección por $H$. pylori, principalmente CG en edad adulta ${ }^{54}$.

Por otro lado, el fracaso de la erradicación aumenta el riesgo de resistencia antimicrobiana secundaria, y la persistencia de infección tiene numerosas repercusiones en la salud y en aspectos económicos para el paciente $^{55}$. Por estas razones, estamos totalmente de acuerdo con que idealmente la susceptibilidad a antimicrobianos debería determinarse en todas las cepas infectantes.

Sin embargo, algunos ajustes son necesarios en el contexto de LA: i) las técnicas moleculares y de cultivo basadas en biopsias no están disponibles en nuestros países, e incluso cuando están disponibles se limitan a los laboratorios de investigación en las grandes ciudades$^{7}$; ii) cuando se realizan estudios en países con gran extensión territorial como Argentina y Brasi ${ }^{56}$, o incluso un poco más pequeños como Bolivia, Chile, Colombia, México y Venezuela, los investigadores no pueden afirmar que un estudio de susceptibilidad antimicrobiana realizado en una región o ciudad específica del país represente el patrón de resistencia de todo el país ${ }^{57}$.

Desafortunadamente, hay pocos informes pediátricos. Una revisión sistemática en LA arrojó 59 estudios sobre resistencia a los antimicrobianos de $H$. pylori ( 56 en adultos, 2 en niños y 1 en ambos grupos), donde los informes pediátricos eran muy pocos para resumirlos mediante un metaanálisis ${ }^{43}$. La resistencia a metronidazol (MET) y a claritromicina (CLA) parece ser la causa principal del fracaso de la erradicación, con datos controversiales respecto a la importancia relativa de cada uno. Algunos estudios recientes en pacientes pediátricos muestran una alta prevalencia de resistencia a CLA en niños chilenos (21\%) y brasileños $(19,5 \%)^{53,54}$, sin embargo, un estudio reciente en Bogotá, Colombia, 
encontró solamente un $8 \%$ de cepas asociadas con resistencia a CLA ${ }^{58}$.

Es probable que el enfoque del IV Consenso Brasileño sobre infección por $H$. pylori sea la guía clínica mejor adaptada a LA, ya que se destaca que las pruebas de susceptibilidad no están ampliamente disponibles en nuestro medio, por esa razón no recomiendan la realización rutinaria de pruebas de susceptibilidad. Sin embargo, después del segundo o tercer fracaso de erradicación hay recomendación de que se debe realizar la prueba de susceptibilidad ${ }^{6}$.

En niños, por otro lado, la oferta de antimicrobianos es menor, por ejemplo: el uso de tetraciclina y levofloxacino no se recomienda. Entonces, conocer adecuadamente el patrón de resistencia antimicrobiana y personalizar el tratamiento de erradicación para optimizar el resultado se vuelve de crucial importancia en pediatría.

Recomendación 11a SLAGHNP: Idealmente, donde y cuando las pruebas de susceptibilidad estén disponibles, se debe determinar el patrón de resistencia a antimicrobianos para orientar el primer intento de erradicar la infección.

Nivel de evidencia: I

Grado de recomendación: $\quad$ A

Grado de acuerdo PROMEDIO: 4

Recomendación 11b SLAGHNP. Cuando estén disponibles, se deben realizar pruebas de susceptibilidad antimicrobiana en pacientes pediátricos para mejorar la efectividad del tratamiento de erradicación, particularmente si hay alta prevalencia $(>20 \%)$ de resistencia a CLA.

Nivel de evidencia: I

Grado de recomendación: $\quad$ A

Grado de acuerdo PROMEDIO: 4

\section{Sobre el estudio de susceptibilidad a antimicrobianos de $\mathrm{H}$. pylori frente al fracaso del tratamiento de erradicación de $H$. pylori a nivel regional (Recomendación 12)}

\section{Puntos práctico}

a. Como la prueba de susceptibilidad a antimicrobianos no está disponible en todos los centros, proponemos que se evalúe la eficacia de los regímenes de erradicación de $H$. pylori en niños y adolescentes, de ser posible a nivel regional.

\section{Comentarios}

Nosotros apoyamos la afirmación original de NASPGHAN/ESPGHAN, en particular, que el fracaso del tratamiento de erradicación de $H$. pylori en la prácti- ca clinica frecuentemente se asocia con una elección inadecuada del régimen de tratamiento, falta de adherencia o resistencia a antimicrobianos. Para evitar investigaciones adicionales, y la inducción de resistencia secundaria en las cepas de $H$. pylori infectantes, la tasa de éxito primario para erradicación debe ser más del $90 \%$ en el análisis por protocolo. Este objetivo no se alcanza en la mayoría de los ensayos de tratamiento publicados actualmente en niños ${ }^{57,59}$. Por lo tanto, la evaluación comparativa es una necesidad para evaluar el desempeño local de los regímenes prescritos y para minimizar el riesgo de fracaso del tratamiento. Esto es de particular importancia en áreas en las que no se dispone de pruebas de susceptibilidad antimicrobiana.

Martínez y cols. realizaron una revisión de 35 publicaciones (1996 a 2012) que agruparon en total 3.358 muestras aisladas, 3.262 provenían de pacientes adultos y 96 de niños en diferentes países: Brasil 9, Colombia 8, México 5, Chile 4, Perú, Costa Rica, Argentina, Ecuador, Jamaica, Paraguay, Uruguay y Venezuela ${ }^{57}$. Las técnicas utilizadas para determinar la sensibilidad antibiótica del $H$. pylori fueron: el E-test (épsilon test) en 17 estudios (48\%), la dilución en agar 14 estudios (37\%) y la difusión en disco 3 (8\%). Los estudios presentaron bastante heterogeneidad y diferencias entre los países de la región e incluso en estudios realizados en un mismo país. La resistencia in vitro para MTZ fue de $65,7 \%$, para AMO de 6,5\%, para CLA de $14 \%$, para tetraciclina de $8,3 \%$, para levofloxacina de $39 \%$ y para furazolidona de 6,9\%. Estudios basados en técnicas moleculares y mas recientes en pacientes pediátricos muestran una alta prevalencia de resistencia a CLA en pacientes pediátricos chilenos $(21 \%)$ y brasileños $(19,5 \%)^{60,61}$, sin embargo, en pacientes pediátricos sintomáticos de Colombia la resistencia a la CLA fue solamente del $8 \%{ }^{58}$.

Un trabajo prospectivo, multicéntrico europeo, estudió la resistencia a antibióticos de más de 1.000 niños a los que se les realizó EDA; se detectó $24 \%$ de resistencia primaria a claritromicina, más alta en varones, en niños menores de 6 años comparado con los de más de 12 años, y en pacientes del sur de Europa (Grecia, Italia, España y Portugal). La resistencia a MTZ fue del $25 \%$, más alta en niños nacidos fuera de Europa. La resistencia a $\mathrm{AMO}$ fue excepcional, el 0,6\%, y la doble resistencia a CLA y MTZ, del 6,9\% ${ }^{62}$.

No se encontraron estudios epidemiológicos respecto a costo y disponibilidad de técnicas para evaluar sensibilidad antimicrobiana en centros de referencias regionales o nacionales de países de LA; por lo tanto, la recomendación 12 de NASPGHAN/ESPGHAN debería también aplicarse en LA.

El H. pylori es un agente infeccioso y el objetivo terapéutico debería ser siempre el $100 \%$, habiéndose establecido un umbral teórico de eficacia (excelente > 
$95 \%$, bueno $90-95 \%$, regular $85 \%-89 \%$, malo $81 \%$ $84 \%$ e inaceptable $80 \%)^{63}$. El escenario ideal, por lo tanto, sería conocer de antemano la susceptibilidad a antibióticos del microorganismo mediante cultivo de bacteria u otra técnica molecular, para diseñar un tratamiento a la medida para cada cepa de $H$ pylori. Tal y como se ha mencionado con anterioridad, la realidad es que la gran mayoría de los tratamientos de erradicación se prescriben de forma empírica ${ }^{63-65}$. Por tanto, esta elección se debe hacer teniendo en cuenta variables dependientes de la bacteria y del individuo. Se deberían conocer las tasas de resistencia a antibióticos locales, y en caso de desconocerlas, hacer una estimación de las mismas según la eficacia local de los tratamientos utilizados ${ }^{63,65}$.

Recomendación 12 SLAGHNP: Recomendamos que el estudio de sensibilidad o resistencia antimicrobiana de $H$. pylori sea evaluado en centros regionales seleccionados que actúen como centros de referencia para todos los países de LA.

Nivel de evidencia: III

Grado de recomendación: B

Grado de acuerdo PROMEDIO: 4

\section{Sobre la elección del tratamiento antibiótico para erradicar H. pylori (Recomendación 14)}

\section{Puntos prácticos}

a. Si la cepa es susceptible a CLA y MET, la opción preferida es la terapia triple (IBP, AMO, CLA) durante 14 días. En caso de fracaso del tratamiento se puede hacer un cambio a IBP, AMO y MET, sin más pruebas de susceptibilidad. b. La terapia secuencial durante 10 días (IBP con AMO durante 5 días, seguido de IBP con CLA y MET durante 5 días, según dosis en la tabla 4) es igualmente eficaz que la terapia triple en pacientes infectados con cepas totalmente susceptibles. Sin embargo, tiene la desventaja de exponer al niño a 3 antibióticos diferentes. No debe administrarse terapia secuencial si la cepa es resistente a MET o CLA, o si no se dispone de pruebas de sensibilidad. En adultos, sin embargo, las pautas más recientes recomiendan el uso de terapia secuencial como terapia de primera o segunda línea.

c. Las dosis de IBP y antibióticos deben calcularse según el peso corporal (tabla 4).

d. Un mayor grado de supresión ácida mejora la tasa de éxito de la terapia basada en AMO y CLA. Los niños más pequeños necesitan una dosis más alta de IBP por kg de peso corporal en comparación con los adolescentes y adultos para obtener una supresión de ácido suficiente.

e. Esomeprazol y rabeprazol son menos susceptibles a la degradación por metabolizadores rápidos con polimorfismo genético del CYP2C19 y, por lo tanto, pueden preferirse cuando estén disponibles. Los metabolizadores rápidos son más frecuentes en la población caucásica (56\%-81\%) en comparación con los asiáticos. No contamos con datos publicados en población pediatrica en LA, pero un estudio en adultos chilenos evidenció un 79,5\% de metabolizadores rápidos ${ }^{66}$.

f. La dosis de IBP dada en la tabla 4 se refiere a esomeprazol y omeprazol y debe adaptarse si se usan otros IBP. Los IBP deben administrarse preferentemente al menos 15 min antes de la comida.

Tabla 4. Régimen de dosificación estándar

\begin{tabular}{cccc}
\hline Medicamento & Rango de peso & Dosis matinal $(\mathrm{mg})$ & Dosis vespertina $(\mathrm{mg})$ \\
\hline IBP* & $15-24 \mathrm{~kg}$ & 20 & 20 \\
& $25-34 \mathrm{~kg}$ & 30 & 30 \\
& $>35 \mathrm{~kg}$ & 40 & 40 \\
Amoxicilina & $15-24 \mathrm{~kg}$ & 500 & 700 \\
& $25-34 \mathrm{~kg}$ & 750 & 1.000 \\
& $>35 \mathrm{~kg}$ & 1.000 & 250 \\
Claritromicina & $15-24 \mathrm{~kg}$ & 250 & 250 \\
& $25-34 \mathrm{~kg}$ & 500 & 500 \\
Metronidazol & $>35 \mathrm{~kg}$ & 500 & 250 \\
& $15-24 \mathrm{~kg}$ & 250 & 250 \\
& $25-34 \mathrm{~kg}$ & 500 & 500 \\
\hline
\end{tabular}

*IBP, Inhibidor de Bomba de Protones. ${ }^{*}$ QID, cuatro veces al día. 
g. Para los niños menores de 8 años, la terapia cuádruple de bismuto se refiere a bismuto, PPI, AMO y MET. En niños mayores de 8 años, la terapia cuádruple de bismuto se refiere a bismuto, PPI, MET y tetraciclina.

h. La evidencia actual no respalda adición de rutina de probióticos individuales o combinados a la terapia de erradicación para reducir los efectos secundarios y/o mejorar las tasas de erradicación.

\section{Comentarios}

El esquema recomendado en caso de no conocer la susceptibilidad antimicrobiana del $H$. pylori incluye dosis altas de IBP-AMO-MET (14 días) o terapia cuádruple con bismuto. Los escasos estudios que reportan resistencia in vitro para diferentes antibióticos ya han sido descritos mas arriba ${ }^{57,60,61,67,68}$.

Ramírez-Bulla realizó una revisión sistemática para determinar la prevalencia de resistencia de $H$. pylori a tetraciclina, encontrando un $8 \%$ en Centro y Sur América $^{69}$, dato a considerar en los esquemas de tratamiento para niños mayores de 8 años. Thiebaud realizó un estudio retrospectivo en Honduras, en niños menores de 11 años con enfermedad por $H$. pylori que recibieron tratamiento con AMO $60 \mathrm{mg} / \mathrm{kg} /$ día, CLA $20 \mathrm{mg} /$ $\mathrm{kg}$ /día y lanzoprazol $30 \mathrm{mg}$ /día por 14 días. El 79,2\% de los pacientes reportó mejoría clínica y antígeno fecal negativo posterior al tratamiento ${ }^{70}$.

Los hallazgos de Martínez y cols. descritos en la sección previa ${ }^{57}$ y la falta de publicaciones con datos actualizados respecto a resistencia antibiótica de $H$. pylori en LA y la valoración de la eficacia de esquemas de primera línea harían que el esquema recomendado en la guía NASPGHAN/ESPGHAN, en caso de no conocer la susceptibilidad antimicrobiana, no sea aplicable en la población pediátrica latinoamericana.

Recomendación 14 SLAGHNP: Recomendamos usar la tabla adjunta (tabla 5) como tratamiento de primera línea para la infección por $H$. pylori en caso de conocerse la susceptibilidad antimicrobiana. En caso de no conocerse la susceptibilidad recomendamos el esquema de IBP-AMO-CLA por 14 días a dosis estándar (excepto en países con resistencia a CLA > 20\%).
Nivel de evidencia: II

Grado de recomendación: B

Grado de acuerdo PROMEDIO: 4

\section{Sobre como evaluar la erradicación de H. pylori posterior al tratamiento antibiótico (Recomendación 15)}

\section{Puntos Prácticos}

a. Existe evidencia de una resistencia creciente del H. pylori a los esquemas antibióticos usados en la actualidad, lo cual puede resultar en fallas en la erradicación de la infección con las complicaciones que resultan de una infección crónica ${ }^{46,57,71}$. Nos parece prudente comprobar la erradicación de la infección después del tratamiento. Mera y colaboradores publicaron un estudio de seguimiento durante 16 años en adultos colombianos en una región de alta incidencia de $H$. pylori demostrando como un tratamiento efectivo de erradicación condujo a una disminución de lesiones pre malignas y aún a la regresión de ellas ${ }^{72}$.

b. Para comprobar la eficaz erradicación de la infección se reconocen métodos invasivos utilizando la EDA con toma de biopsias para histología, RUT y cultivo. Dado su carácter invasivo y altos costos se consideran poco favorables en niños y se prefieren métodos no invasivos ${ }^{73}$.

c. Queiroz y cols. reportaron un estudio de concordancia, realizado en Brasil, comparando el UBTC13 y el HpSAg, usando un test comercial de ELISA (Premier Platinum HpSa Plus Assay con múltiples antígenos monoclonales murinos) encontrando una concordancia del $94,9 \%$ entre los dos exámenes ${ }^{74}$.

d. Los test no invasivos incluyen el UBT-C13 el cual ha demostrado una sensibilidad y especificidad superiores al 95\%, especialmente en niños mayores de 6 años (Sensibilidad: 96,6\%, especificidad: $97,7 \%)$. En menores de 6 años su exactitud es menor (sensibilidad: 95\%, Especificidad: 93,5\%) debido posiblemente a una menor producción endógena de $\mathrm{CO}_{2}{ }^{73-77}$.

Tabla 5. Terapia de primera línea para infección por $\boldsymbol{H}$. pylori con susceptibilidad conocida

\begin{tabular}{|c|c|}
\hline Susceptibilidad & Tratamiento sugerido \\
\hline Susceptible a CLA* y MET** & $\mathrm{IBP} \wedge-\mathrm{AMO}^{* * *}$-CLA $14 \mathrm{~d}$ a dosis estándar \\
\hline Resistente a CLA, susceptible a MET & IBP-AMO-MET 14d o esquema de bismuto \\
\hline Resistente a MET, susceptible a CLA & IBP-AMO-CLA 14d o esquema de bismuto \\
\hline Resistente a CLA y MET & IBP-AMO-MET con dosis altas de AMO o esquema de bismuto \\
\hline
\end{tabular}


e. El HpSAg ha demostrado ser tan eficiente como el UBT-C13 y presenta algunas ventajas pues la muestra se toma fácilmente, puede transportarse y su procesamiento puede ser realizado si se mantiene refrigerado en sitios de referencia lejanos a su sitio de captación ${ }^{76-78}$. Los métodos de detección de antígenos policlonales y los monoclonales de un paso no se recomiendan debido a su inexactitud ${ }^{76}$.

\section{Comentarios}

Comprobar que los tratamientos instaurados en nuestros pacientes sean efectivos en la erradicación del $H$. pylori es una meta deseable para disminuir las complicaciones de la infección como UGD, hemorragia digestiva, anemia por deficiencia de hierro y la posibilidad de desarrollar CG.

Los métodos no invasivos, UBT-C13 y HpSAg monoclonal en materia fecal han demostrado tener una sensibilidad y especificidad de alrededor del 95\%, en la mayoría de los estudios consultados, y resultan mas fáciles de realizar en niños. El uso de antibióticos y/o de IBP durante el mes anterior a la toma de endoscopia pueden inducir falsos negativos al disminuir la población de $H$. pylori o al disminuir la producción de ácido gástrico $^{79}$.

En algunos países de LA se encuentran disponibles métodos de detección de UBT-C13 que pueden ser tomados en los consultorios y transportados al laboratorio para su realización. En Colombia y Chile se dispone del test en forma comercial con un valor promedio de US\$ 70-100 para el usuario final.

Recomendación 15a SLAGHNP: Se recomienda comprobar el éxito del tratamiento anti $H$. pylori utilizando el UBT-C13 o HpSAg.

Nivel de evidencia: I

Grado de recomendación: A

Grado de acuerdo PROMEDIO: 4

Recomendación 15b SLAGHNP: Los test deben realizarse al menos 4 semanas después de recibir el tratamiento antibiótico y de la suspensión de los inhibidores de bomba de protones.

Nivel de Evidencia: I

Grado de recomendación: A

Grado de acuerdo PROMEDIO: 4

\section{Sobre la elección del tratamiento antibiótico de segunda línea para erradicar $H$. pylori (Recomendación 16)}

\section{Puntos prácticos:}

a. Si bien el ideal es contar con el perfil de susceptibilidad antibiótica de $H$. pylori desde el primer momento, de manera de poder indicar un tratamiento de primera línea de acuerdo a éste, en la práctica esto es difícil de lograr en gran parte de LA. En general, los estudios de susceptibilidad antibiótica se reservan para centros grandes y con fines de investigación.

b. La tasa de erradicación del tratamiento de primera línea en niños es inferior a la reportada en adultos y fluctúa entre $64 \%$ a $77 \%{ }^{80-82}$. A esto se suma, que el repertorio de antibióticos que es posible administrar en niños es más reducido que a edades posteriores, por motivos de seguridad, lo que reafirma la necesidad de contar con un estudio de susceptibilidad antimicrobiana en casos de falla del tratamiento de primera línea, de manera de poder escoger el esquema antibiótico más adecuado.

\section{Comentarios}

Nosotros estamos de acuerdo con la afirmación 16 de NASPGHAN/ESPGHAN, aunque estamos conscientes de que su implementación en el contexto actual de salud en LA es difícil. La evidencia en adultos demuestra que el tratamiento guiado por antibiograma es más efectivo que el empírico tanto de primera línea ${ }^{52}$ como de rescate ${ }^{83}$. Si bien el sentido común sugiere que esta estrategia también es recomendable en niños, no existen estudios pediátricos que hayan explorado la efectividad del tratamiento personalizado según susceptibilidad antimicrobiana comparado con empírico.

La implementación de esta recomendación implica realizar una nueva EDA con toma de biopsia gástrica para cultivo y estudio de susceptibilidad a antibióticos. El cultivo de $H$. pylori requiere su siembra en medios especiales e incubación por 7-10 días, seguido por 24$48 \mathrm{~h}$ de incubación del test de susceptibilidad antimicrobiana. En la práctica este estudio se realiza en pocos centros terciarios de LA y en general con fines de investigación. Nosotros recomendamos fuertemente que la técnica de cultivo y antibiograma para $H$. pylori esté disponible en todo centro en donde se realice EDA pediátrica y que este sea tomado al menos en todo paciente que ha fracasado al tratamiento de segunda línea. Esto con el fin de escoger el esquema más adecuado para lograr una erradicación efectiva luego del fracaso de terapia de segunda línea.

Dado que algunos de los antibióticos incluidos en los esquemas de erradicación de $H$. pylori pueden tener reacciones adversas en niños, que no se presentan en adultos (como quinolonas y tetraciclinas), su uso debe estar plenamente respaldado y reservarse sólo para casos con resistencia demostrada a los antimicrobianos más seguros. Basado en los perfiles de resistencia descritos en niños latinoamericanos ${ }^{57,60,84}$ y de otras latitudes $^{85-88}$, se recomienda incluir dentro del estudio al menos susceptibilidad a AMO, CLA, MET, tetraciclina y ciprofloxacino ( $\mathrm{u}$ otra quinolona). 
La guía publicada más reciente en LA para el manejo de casos en adultos, es la Brasileña, que considerando las dificultades prácticas de implementar el estudio de susceptibilidad para H. pylori, sugiere esquemas empíricos de primera, segunda y tercera línea, reservando el cultivo y antibiograma para el manejo de casos luego de una tercera falla de tratamiento ${ }^{6}$. Desaconsejamos esta práctica en niños y recomendamos apoyar la elección de antibióticos con estudio de susceptibilidad desde la segunda falla de tratamiento, debido a que el uso indiscriminado de antibióticos puede tener serio impacto en la salud del paciente, su microbiota y favorecer la aparición de resistencia secundaria.

Recomendación 16a SLAGHNP: En caso de falla de erradicación de H. pylori con el tratamiento de primera línea, recomendamos tratamiento empírico con terapia cuádruple con bismuto. En menores de 8 años, se recomienda esquema con inhibidor de bomba de protones, AMO, MET y bismuto por 14 días. En niños de 8 años y más, se puede considerar reemplazar el MET por tetraciclina en este mismo esquema.

Nivel de evidencia: I (en adultos)

Nivel de recomendación: A

Grado de acuerdo PROMEDIO: $\quad 3,8$

Recomendación 16b SLAGHNP: En caso de falla de erradicación con el esquema de segunda línea, se recomienda indicar un tratamiento individualizado considerando idealmente la sensibilidad antibiótica de la cepa (lo que implica realizar una nueva endoscopía con extracción de muestra para cultivo y antibiograma o estudio molecular de resistencia), el esquema indicado previamente y la edad del paciente.

$\begin{array}{ll}\text { Nivel de evidencia: } & \text { I (en adultos) } \\ \text { Nivel de recomendación: } & \text { A } \\ \text { Grado de acuerdo PROMEDIO: } & 3,8\end{array}$

\section{Sobre la prevención de cáncer gástrico en niños infectados}

Las guías clínicas de NASPGHAN/ESPGHAN 2011 afirmaban el "Consider testing in the setting of family history of gastric cancer or MALT", sin embargo, en la nueva versión 2016, remueven dicha recomendación: "Removal of recommendation for testing of the setting of family history of gastric cancer or MALT, as rarely encountered".

\section{Puntos Prácticos}

a. Según reportes del Global Cancer Observatory (Globocan), hay más de 900.000 nuevos casos de CG cada año y mas de 700.000 fallecidos por año, convirtiéndose en la $5^{\circ}$ causa en incidencia anual por tumores malignos y $3^{\circ}$ causa en mortalidad por cáncer en el mundo y en LA con graves implicancias socio-económicas (https://gco.iarc.fr/). Las incidencias ajustadas por edad y sexo son significativamente mayores en los países en vías de desarrollo en comparación con los países desarrollados. En la actualidad 3 países concentran el $60 \%$ del total de CG del mundo, que corresponden a Japón, China y Corea. En LA, la incidencia de CG da cuenta del 6\%-7\% de la incidencia total mundial, duplicando a la de Europa y triplicando a la de EE. UU. ${ }^{89}$.

b. La relación entre prevalencia de infección por $H$. pylori e incidencia de CG ha quedado bien establecida $^{90}$. La incidencia de CG está generalmente en proporción directa a la prevalencia de la infección por $H$. pylori, aun cuando hay incidencias mayores de CG en países asiáticos comparados con otros países con similares prevalencias de la infección ${ }^{91}$. La virulencia de las cepas ha sido establecida como uno de los factores centrales en el desarrollo de $\mathrm{CG}^{92}$.

c. Existe evidencia de la trasmisión intrafamiliar de la infección por H. pylori, en particular de padres a hijo, de modo que los niños reciben cepas de similares características de virulencia que sus padres. Los estudios de genotipificación bacteriana permiten trazar el origen de la infección en niños ${ }^{93-96}$. Pero también, estos niños heredan de sus padres "factores de riesgo" para el desarrollo de CG, tales como polimorfismo de citokinas (IL-17A-197a, IL-17F 7488CC, MMP9-1562 C/T, EGF +61 A>G, CTLA-4 -1661A/G; rs9904341; IL1-RN VNTR; entre otros $)^{97-100}$. Finalmente, estos niños comparten factores de riesgo ambiental como alimentación, exposición a contaminantes u otros de tipo geográfico. Por ello, aquellos niños con familiares infectados de primer grado (los padres o hermanos) o de segundo grado (abuelos o tíos), representan un grupo singular ya que adquieren el $H$. pylori de sus padres y al mismo tiempo comparten factores de riesgo genéticos y ambientales.

Estudios recientes sugieren que el riesgo de desarrollar CG en sujetos con historia familiar de CG es alto con ORs que van desde 1,5 (95\% IC: 1,3$1,8)$ hasta 10,1 (95\% IC: 6,1-16,8) ${ }^{100}$. En un reciente meta-análisis del 2017, tanto de países asiáticos como no asiáticos, con 26 estudios que analizaron exclusivamente la historia de CG en familiares de primer grado, el riesgo fue 2,71 (95\% CI 2,08-3,53; $\mathrm{p}<0,00001)^{100}$. Más aún, entre las personas con antecedentes familiares de CG, el mayor riesgo de desarrollar CG fue: infección por H. pylori actual o pasada, tener dos o más parientes afectados de primer grado y el sexo femenino ${ }^{101}$. 
d. La erradicación del $H$. pylori parece ser la estrategia más importante para prevenir el CG en familiares de primer grado de pacientes con CG, particularmente aquellos en sus 20 y 30 años y prevenir la progresión a metaplasia intestinal ${ }^{101}$, pero no hay datos disponibles en familiares de primer o segundo grado. Un estudio de 750 niños (390 infectados, $52 \%)$ mostró una mayor prevalencia de historia familiar de CG en niños infectados y que en aquellos infectados con atrofia $(6,2 \%)$ y metaplasia intestinal $(2,8 \%)$, la erradicación era capaz de revertir ambos hallazgos ${ }^{102}$.

e. Un meta-análisis de RCTs sobre erradicación de $H$. pylori estudió el efecto sobre la ocurrencia posterior de CG en población general adulta. Este proporciona evidencia de calidad limitada y moderada de que la búsqueda y erradicación de $H$. pylori reduce la incidencia de CG en individuos asiáticos infectados asintomáticos sanos, pero estos datos no necesariamente pueden extrapolarse a otras poblaciones ${ }^{103,104}$. Un modelo que proyecta la posible reducción del riesgo de CG vitalicio y los costos asociados en una región de alto riesgo en China, descubrió que la erradicación entre los 20 a 30 años es más costo-efectiva en comparación con las edades mayores ${ }^{105}$. En el consenso de $\mathrm{LA}^{7}$ se postuló que la erradicación de $H$. pylori en prevención primaria de CG en adultos es deseable, pero reconocen que aun no hay evidencia suficiente para implementarlo a gran escala en la población general (Nivel de Evidencia tipo I, Grado de recomendación C). Los meta-análisis de aquellos RCT orientado a prevención de CG, sugieren que la erradicación de $H$. pylori significativamente reduce el riesgo de CG (RR 0,6; 95\% CI: 0,4-0,9), especialmente en poblaciones de alto riesgo, pero no hay datos empíricos que aborden la edad más apropiada para las intervenciones para erradicar la infección por $H$. pylori. El mas reciente meta-análisis del 2017, demuestra que la reducción de riesgo relativo de ocurrencia de CG fue de 0,67 (95\% CI: $0,48-0,95)^{106}$.

\section{Comentarios}

En una reciente revisión de investigadores de LA, se identificaron 37 biomarcadores de CG, de los cuales 24 están sobre expresados, 3 están sub expresados, y 10 genes están significativamente hipermetilados en niños infectados por $H$. pylori comparados con niños no infectados. Es destacable que 13 de estos biomarcadores (b-catenina, C-MYC, GATA-4, DAPK1, CXCL13, DC-SIGN, TIMP3, EGFR, GRIN2B, PIM2, SLC5A8, $\mathrm{CDH} 1$, and VCAM-1) están consistentemente desregulados en niños y adultos con CG. Sin embargo, a la fecha, no es posible aun identificar que niños familia- res de pacientes con CG podrían estar en un riesgo mayor de desarrolla lesiones pre neoplásicas ${ }^{107}$.

Desde el año 2013 ya existen consensos importantes (IARC 2013, Kyoto 2014) ${ }^{108,109}$ que han entregado argumentos adicionales apoyando la estrategia de erradicar en población asintomática para prevención de CG. Adicionalmente hay en curso grandes estudios de erradicación cuyos resultados estarán disponibles para 2019 y 2020. Sin embargo, no hay información sobre la efectividad de la erradicación en familiares de primer y segundo grado de pacientes con CG, es altamente probable que los beneficios en población general se repitan o amplifiquen en población de alto riesgo.

Este año 2020, Choi et al., reportó el resultado de un estudio de 1.676 sujetos con historia familiar de CG en familiares de primer grado (9,2 años de seguimiento) mostrando que entre los 832 sujetos infectados con $H$. pylori, la erradicación de la bacteria redujo el riesgo de desarrollar CG, comparado con los 844 sujetos infectados que no recibieron tratamiento (RR 0,27; 95\% CI, $0,10-0,70)^{110}$. Considerando el beneficio de la población general de su erradicación, la patogenia asociada a CG y las altas incidencias de CG en LA, optamos por recomendar erradicar la bacteria cuando ésta es encontrada en una endoscopia de niño sintomático referido a endoscopía con antecedente de familiares de primer o segundo grado con historia de cáncer gástrico.

Recomendación SLAGHNP: En niños sintomáticos referidos a endoscopía, con antecedente de familiares de primer o segundo grado con cáncer gástrico, recomendamos buscar $H$. pylori (y erradicar cuando es detectado), mediante técnica directa durante la endoscopia.

Nivel de evidencia: III

Nivel de recomendación: $\quad$ B

Grado de acuerdo PROMEDIO: $\quad 3,6$

\section{Conclusiones}

El panel de especialistas ha evaluado las actuales recomendaciones de NASPGHAN/ESPGHAN 2016, basado en los datos actuales de LA. Se establecieron de manera consensuada las afirmaciones de interés en relación a diagnóstico, prevención y tratamiento de la infección por $H$. pylori en niños, las cuales se resumen en la tabla 6. La evidencia apoya mayoritariamente los conceptos generales expuestos en las Guías NASPGHAN/ESPGHAN 2016, pero es necesario adaptarlas a la realidad de LA con énfasis en el desarrollo de centros regionales para el estudio de sensibilidad a antibióticos y mejorar la correcta selección del tratamiento de erradicación. Es necesario considerar la bús- 
Tabla 6. Resumen de Recomendaciones

\begin{tabular}{|c|c|}
\hline $\begin{array}{l}N^{\circ} \text { de Recomendación } \\
\text { NASPGHAN/ESPGHAN }\end{array}$ & Propuesta de SLAGHNP \\
\hline $2 a$ y $2 b$ & $\begin{array}{l}\text { 2a. Recomendamos la toma de biopsia para RUT e histología (y biopsias para cultivo o técnicas moleculares, cuando } \\
\text { esté disponible) durante la endoscopia digestiva alta, sólo si se administrará tratamiento en caso de confirmar la } \\
\text { infección } \\
\text { 2b. Recomendamos que si la infección por } \mathrm{H} \text {. pylori es un hallazgo fortuito en la endoscopia, el tratamiento puede } \\
\text { ser considerado con una detallada discusión del mismo con el paciente y sus padres }\end{array}$ \\
\hline 4 & $\begin{array}{l}\text { En niños con dolor abdominal funcional, en ausencia de señales de alarma, se desaconseja la realización de test para } \\
\text { búsqueda de } H \text {. pylori. En niños con dispepsia o dolor abdominal con señales de alarma de acuerdo a los criterios } \\
\text { Roma IV, se recomienda como primera opción realizar endoscopia digestiva alta, para determinar la presencia de } \\
\text { lesiones y otras causas de dolor abdominal. En caso de identificar alguna lesión (úlcera, erosiones), se recomienda } \\
\text { tomar biopsias para RUT e histología y de estar disponible, también biopsias para cultivo o técnicas moleculares. } \\
\text { En caso de identificar H. pylori, debe considerarse tratamiento de erradicación }\end{array}$ \\
\hline $9 a$ y $9 b$ & $\begin{array}{l}\text { 9a. El diagnóstico de infección por } \mathrm{H} \text {. pylori debe realizarse en pacientes sintomáticos basado en biopsias obtenidas } \\
\text { por medio de EDA, con al menos dos de las siguientes pruebas positivas: RUT, histología, o cultivo } \\
\text { 9b. Se deben tomar al menos } 5 \text { biopsias gástricas para el diagnóstico de infección por } H \text {. pylori en la EDA. Deben } \\
\text { obtenerse dos biopsias del antro y dos biopsias del cuerpo para la evaluación histopatológica aplicando la clasifica- } \\
\text { ción Sydney y una biopsia de antro para RUT; idealmente podrían tomarse biopsias adicionales si existen técnicas } \\
\text { para estudio de sensibilidad antimicrobiana (cultivo o técnicas moleculares) }\end{array}$ \\
\hline $11 a$ y $11 b$ & $\begin{array}{l}\text { 11a. Idealmente, donde y cuando las pruebas de susceptibilidad estén disponibles, se debe determinar el patrón } \\
\text { de resistencia a antimicrobianos para orientar el primer intento de erradicar la infección } \\
11 \text { b. Cuando estén disponibles, se deben realizar pruebas de susceptibilidad antimicrobiana en pacientes pediá- } \\
\text { tricos para mejorar la efectividad del tratamiento de erradicación, particularmente si hay alta prevalencia (> 20\%) } \\
\text { de resistencia a CLA }\end{array}$ \\
\hline 12 & $\begin{array}{l}\text { Recomendamos que el estudio de sensibilidad o resistencia antimicrobiana de } \mathrm{H} \text {. pylori sea evaluado en centros } \\
\text { regionales seleccionados que actúen como centros de referencia para todos los países de LA }\end{array}$ \\
\hline 14 & $\begin{array}{l}\text { Recomendamos usar la tabla adjunta (tabla 5) como tratamiento de primera línea para la infección por } \mathrm{H} \text {. pylori en } \\
\text { caso de conocerse la susceptibilidad antimicrobiana. En caso de no conocerse la susceptibilidad recomendamos el } \\
\text { esquema de IBP-AMO-CLA por } 14 \text { días a dosis estándar (excepto en países con resistencia a CLA > 20\%) }\end{array}$ \\
\hline 15 & $\begin{array}{l}\text { 15a. Se recomienda comprobar el éxito del tratamiento anti } H \text {. pylori utilizando el UBT-C13 o HpSAg } \\
\text { 15b. Los test deben realizarse al menos } 4 \text { semanas después de recibir el tratamiento antibiótico y de la suspensión } \\
\text { de los inhibidores de bomba de protones }\end{array}$ \\
\hline 16 & $\begin{array}{l}\text { En caso de falla de erradicación con el esquema de segunda línea, se recomienda indicar un tratamiento individua- } \\
\text { lizado considerando idealmente la sensibilidad antibiótica de la cepa (lo que implica realizar una nueva endoscopía } \\
\text { con extracción de muestra para cultivo y antibiograma o estudio molecular de resistencia), el esquema indicado } \\
\text { previamente y la edad del paciente }\end{array}$ \\
\hline Cáncer gástrico & $\begin{array}{l}\text { En niños sintomáticos referidos a endoscopía, con antecedente de familiares de primer o segundo grado con cáncer } \\
\text { gástrico, recomendamos buscar } \mathrm{H} \text {. pylori (y erradicar cuando es detectado), mediante técnica directa durante la } \\
\text { endoscopia }\end{array}$ \\
\hline
\end{tabular}

queda de $H$. pylori (y erradicarlo cuando es detectado), mediante técnica directa durante una endoscopia, en un niño sintomático referido a endoscopía con antecedente de familiares de primer o segundo grado con historia de CG.

Es improbable que ninguna Guía Clínica regional pueda ser implementada en forma global, dadas las diversas realidades socioeconómicas o dado el impacto diferencial de CG en diversos continentes y edades. No obstante, las Guías Clínicas deben ser continuamente revisadas y adaptadas a la evidencia disponible. Finalmente LA es una región particular donde el CG continúa siendo un problema relevante y son necesarios nuevos estudios de cohorte que evalúen el impacto de la erradicación de $H$. pylori en niños y su impacto en la prevención del CG.

\section{Financiamiento}

Fondecyt Chile \#1190456 (YL), Fondecyt Chile \#1130387 (PRH).

\section{Conflicto de intereses}

Los autores declaran no tener conflicto de intereses. 


\section{Referencias}

1. Curado MP, de Oliveira MM, de Araújo Fagundes M. Prevalence of Helicobacter pylori infection in Latin America and the Caribbean populations: A systematic review and meta-analysis. Cancer Epidemiol. 2019;60:141-8.

2. Malfertheiner P, Megraud F, O'Morain CA, et al. and European Helicobacter and Microbiota Study Group and Consensus panel. Management of Helicobacter pylori infection-the Maastricht V/Florence Consensus Report. Gut. 2017;66:6-30.

3. Sugano K, Tack J, Kuipers EJ, et al. Kyoto global consensus report on Helicobacter pylori gastritis. Gut. 2015;64:1353-67.

4. Kim SG, Jung HK, Lee HL, et al. and Korean College of Helicobacter and Upper Gastrointestinal Research. Guidelines for the diagnosis and treatment of Helicobacter pylori infection in Korea, 2013 revised edition. J Gastroenterol Hepatol. 2014;29:1371-86.

5. Liu WZ, Xie Y, Lu H, et al and Chinese Society of Gastroenterology, Chinese Study Group on H. pylori and Peptic Ulcer. Fifth Chinese National Consensus Report on the management of Helicobacter pylori infection. Helicobacter. 2018;23(2):e12475.

6. Coelho LGV, Marinho JR, Genta R, et al. IVth Brazilian Consensus Conference on H. pylori infection. Arq Gastroenterol. 2018;55:97-121.

7. Rollan A, Arab JP, Camargo MC, et al. Management of Helicobacter pylori infection in Latin America: A Delphi technique-based consensus World J Gastroenterol 2014;20:10969-83.

8. Bourke B, Ceponis P, Chiba N, et al. and Canadian Helicobacter Study Group. Canadian Helicobacter Study Group Consensus Conference: Update on the approach to Helicobacter pylori infection in children and adolescents-an evidencebased evaluation. Can J Gastroenterol. 2005;19:399-408. Review. Erratum in: Can J Gastroenterol. 2005 Aug;19(8):478.

9. Jones NL, Koletzko S, Goodman K, et al. Joint ESPGHAN/NASPGHAN guidelines for the management of Helicobacter pylori in children and adolescents (update 2016). J Pediatr Gastroenterol Nutr. 2017;64:991-1003

10. Hasson F, Keeney S, McKenna H. Research guidelines for the Delphi survey technique. J Adv Nurs. 2000;32:1008-15.

11. Harris RP, Helfand M, Woolf SH, Lohr $\mathrm{KN}$, Mulrow CD, Teutsch SM, Atkins D; Methods Work Group, Third US Preventive Services Task Force. Current methods of the US Preventive Services Task Force: a review of the process. Am J Prev Med. 2001;20(3 Suppl):21-35.

12. Sawaya GF, Guirguis-Blake J, LeFevre
M, Harris R, Petitti D; U.S. Preventive Services Task ForceUpdate on the methods of the U.S. Preventive Services Task Force: estimating certainty and magnitude of net benefit. Ann Intern Med. 2007;147:871-5.

13. Sierra MS, Hastings EV, Goodman KJ. What do we know about benefits of H. pylori treatment in childhood? Gut Microbes 2013;4:549-67.

14. Harris PR, Wright SW, Serrano C, et al. $H$. pylori gastritis in children is associated with a regulatory $\mathrm{T}$-cell response. Gastroenterology 2008;134:491-9.

15. Melo FF, Rocha AM, Rocha GA, et al. A regulatory instead of an IL-17 response predominates in $H$. pylori associated gastritis in children. Microb Infect 2012;14:341-7.

16. Morgan DR, Torres J, Sexton R, et al. Risk of recurrent $H$. pylori infection 1 year after initial eradication therapy in 7 Latin American communities. JAMA:2013;209:578-86.

17. Sivapalasingam S, Rajasingham A, Maugj $\mathrm{T}$, et al. Recurrence of $H$. pylori infection in Bolivian children and adults after a population-based "screen and treat" strategy. Helicobacter 2014;19:343-8.

18. Blaser MJ, Chen Y, Reibmen J. Does Helicobacter pylori infection protect against asthma and allergy? Gut 2008;57:51-7.

19. Hyams J, Di Lorenzo C. Childhood Functional Gastrointestinal Disorders: Child/Adolescent. Gastroenterology 2016;150:1456-68.

20. Schmulson MJ, Drossman D. What Is New in Rome IV. J Neurogastroenterol Motil 2017;23:151-63.

21. Velasco-Benítez CA, NicholsVinueza D, Saps M. Spanish version of the Questionnaire on Pediatric Gastrointestinal Symptoms-Rome III (QPGS-RIII). J Pediatr Gastroenterol Nutr 2011;53 (suppl 1):E65.

22. Jativa E, Velasco-Benítez C, Saps M, et al. Prevalence of Functional Gastrointestinal Disorders in School children in Ecuador. Pediatr Gastroenterol Nutr 2016;63:25-8.

23. Saps M, Nichols-Vinueza DX, Rosen JM, et al. Prevalence of functional gastrointestinal disorders in Colombian school children. J Pediatr. 2014;164:542-5. e1

24. Phatak UP, Pashankar DS. Prevalence of functional gastrointestinal disorders in obese and overweight children. Int J Obes (Lond) 2014;38:1324-7.

25. Pacifico L, Osborn JF, Tromba V, Romaggioli S, Bascetta S, Chiesa C. Helicobacter pylori infection and extragastric disorders in children: A critical update World J Gastroenterol 2014;20:1379-401.

26. Klein PD, Gilman RH, Leon-Barua R,
Díaz F, Smith EO, Graham DY. The epidemiology of Helicobacter pylori in Peruvian children between 6 and 30 months of age. Am J Gastroenterol 1994;89:196-200.

27. Ramírez-Ramos, Alberto; Gilman, Robert H, Watanabe-Yamamoto, José; Rosas-Aguirre, Angel. Estudio de la epidemiología de la infección por el Helicabacter pylori en el Perú: 20 años. Acta Gastroenterol Latinoam 2004;34:6978.

28. Gottrand F, Vincent P. What Can We Learn from Helicobacter pylori Reinfection in Childhood? J Pediatr Gastroenterol Nutr 2005;40:276-8.

29. Mégraud F, Lehours P. Review Helicobacter pylori detection and antimicrobial susceptibility testing. Clin Microbiol Rev 2007;20:280-322.

30. Jaime F, Villagrán A, Hernández C, Ortiz M, Serrano C, Harris PR. Functional gastrointestinal disorders in children from low socio-economic status and Helicobacter pylori infection. Child Care Health Dev. 2018;44:319-25.

31. Begue RE, Gonzales JL, Correa-Gracian $\mathrm{H}$, Tang SC. $H$. pylori infection in children with abdominal ailments in a developing country. Am J Med Sci. 1997;314:279-83.

32. Queiroz D, Rocha A, Crabtree JE. Unintended consequences of Helicobacter pylori infection in children in developing countries. Gut Microbes 2013;4:494-504.

33. Dixon MF, Genta RM, Yardley JH, et al. Classification and grading of gastritis. The updated Sydney System. International Workshop on the Histopathology of Gastritis, Houston 1994. Am J Surg Pathol 1996;20:1161-81.

34. Yang HR. Updates on the diagnosis of Helicobacter pylori infection in children: what are the differences between adults and children? Pediatr Gastroenterol Hepatol Nutr. 2016;19:96-103.

35. Mejia CR, Vera CA, Huiza-Espinoza L. Association between follicular gastritis and Helicobacter pylori children seen at a public hospital in Peru. Rev Gastroenterol Mex. 2016;81:80-5.

36. Bahú Mda G, da Silveira TR, Maguilnick I, Ulbrich-Kulczynski J. Endoscopic Nodular Gastritis: An Endoscopic Indicator of High-Grade Bacterial Colonization and Severe Gastritis in Children With Helicobacter pylori. J Pediatr Gastroenterol Nutr. 2003;36:217-22.

37. Ikuse T, Ohtsuka Y, Obayashi N. Host response genes associated with nodular gastritis in $H$. pylori infection. Pediatr Int 2018;60:446-54.

38. Mansilla R, Serrano C, Palma C, Vera C, Hernández C, Pizarro M, Torres J, Harris PR, Fuentes-López E, Riquelme A, Espino A. High Helicobacter pylori bacterial load 
and low cytokine expression levels are associated with nodular gastropathy. Digestive Diseases and Sciences 2020;65:565-75.

39. Marulanda H, Otero W, Gómez M. Helicobacter pylori, gastritis nodular y lesiones premalignas de estómago: un estudio de casos y controles. Rev Gastroenterol Peru. 2018;38:349-55

40. Taha M, Hassan A, Samia I, et al. Helicobacter pylori chronic gastritis updated Sydney grading in relation to endoscopic findings and $H$. pylori $\operatorname{IgG}$ antibody: diagnostic methods. J Microsc Ultrastruct. 2016;4:167-74.

41. Rimbara E, Sasatsu M, Graham DY. PCR detection of Helicobacter pylori in clinical samples. Methods Mol Biol 2013;943:27987.

42. Saez J, Belda S, Santibáñez M, et al. Realtime PCR for diagnosing Helicobacter pylori infection in patients with upper gastrointestinal bleeding: comparison with other classical diagnostic methods. J Clin Microbiol 2012;50:3233-7.

43. Camargo MC, García A, Riquelme A, et al. The problem of Helicobacter pylori resistance to antibiotics: a systematic review in LatinAmerica. Am J Gastroenterol 2014;109:485-95.

44. Arévalo A, Otero W, Trespalacios A. Helicobacter pylori: resistencia múltiple en pacientes de Bogotá-Colombia. Biomédica. 2019;39:2-16.

45. Vesga FJ, Moreno Y, Ferrús MA, Campos C, Trespalacios AA. Detection of Helicobacter pylori in drinking water treatment plants in Bogotá, Colombia, using cultural and molecular techniques. Int J Hyg Environ Health. 2018;221:595601.

46. Kotilea K, Kalach N, Homan M, Bontems P. Helicobacter pylori Infection in Pediatric Patients: Update on Diagnosis and Eradication strategies. Paediatr Drugs 2018;20:337-51.

47. Lash RH, Genta RM. Routine antihelicobacter immunohistochemical staining is significantly superior to reflex staining protocols for the detection of Helicobacter in gastric biopsy specimens. Helicobacter. 2016;21:581-5.

48. Nicholson BD, Abel LM, Turner PJ, Price CP, Heneghan C, Hayward G, Plüddemann A. Point-of-care Helicobacter pylori testing: primary care technology update. Br J Gen Pract. 2017;67:576-7.

49. Hooi JKY, Lai WY, Ng WK, et al. Global Prevalence of Helicobacter pylori Infection: Systematic Review and Meta-Analysis. Gastroenterol 2017;153:420-9.

50. Seo JH, Park JS, Yeom JS, et al. Correlation between positive rate and number of biopsy samples on urease test in childhood Helicobacter pylori infection. J Korean Med Sci 2014;29:106-9.
51. Atkinson NS, Braden B. Helicobacter pylori Infection: Diagnostic Strategies in Primary Diagnosis and After Therapy. Digestive diseases and sciences. 2016;61:19-24.

52. Chen H, Dang Y, Zhou X, Liu B, Liu S, Zhang G. Tailored therapy versus empiric chosen treatment for Helicobacter pylori eradication: A meta-analysis. Medicine 2016;95:1-10.

53. López-Góngora S, Puig I, Calvet X, et al. Systematic review and meta-analysis: susceptibility-guided versus empirical antibiotic treatment for Helicobacter pylori infection. J Antimicrobial Chemother 2015;70:2447-55.

54. Ford AC, Gurusamy KS, Delaney B, Forman D, Moayyedi P. Eradication therapy for peptic ulcer disease in Helicobacter pylori-positive people. Cochrane Database Syst Rev. 2016;4:CD003840. doi: 10.1002/14651858.CD003840.pub5.

55. Axon A. Helicobacter pylori and public health. Helicobacter 2014;19(Suppl 1):6873.

56. Vianna JS, Ramis IB, Ramos DF, Von Groll A, Silva PEA. Drug resistance in Helicobacter pylori. Arq Gastroenterol 2016;53I:215-23.

57. Martínez JD, Henao SC, Lizarazo JI. Antibiotic resistance of Helicobacter pylori in Latin america and the Caribbean. Rev Col Gastroenterol 2014;29:217-26.

58. Rosero YL, Arévalo-Jaimes BV, Delgado MP, et al. Evaluation of Helicobacter pylori infection and clarithromycin resistance in strains from symptomatic Colombian children. J Pediatr Gastroenterol Nutr 2018;67:601-4.

59. Arévalo A, Otero W, Trespalacios A. Helicobacter pylori: resistencia múltiple en pacientes de Bogotá, Colombia. Biomédica 2019;39 (Supl.1):125-34.

60. Serrano CA, León MA, Palma C, Vera M, Hernández C, Harris PR. Helicobacter pylori-clarithromycin resistance in symptomatic pediatric patients in a high prevalence country. J Pediatr Gastroenterol Nutr 2017;64:56-60.

61. Ogata SK, Godoy AP, da Silva Patricio FR, Kawakami E. High Helicobacter pylori resistance to metronidazole and clarithromycin in Brazilian children and adolescents. J Pediatr Gastroenterol Nutr 2013;56:645-8.

62. Koletzko S, Richy F, Bontems P, et al. Prospective multicenter study on antibiotic resistence of Helicobacter pylori strains obtained from children living in Europe. Gut 2006;55:1711-6.

63. Molina-Infante J, Corti R, Doweck J, McNicholl A, Gisbert J. Avances recientes en el tratamiento de la infección por Helicobacter pylori. Acta Gastroenterol Latinoam 2017;47(1):75-85.

64. Graham DY, Lee YC, Wu MS. Rational
Helicobacter pylori therapy: evidencebased medicine rather than medicinebased evidence. Clin Gastroenterol Hepatol 2014;12:177-86.

65. Molina-Infante J, Shiotani A. Practical Aspects in Choosing a Helicobacter pylori Therapy. Gastroenterol Clin North Am 2015;44:519-35.

66. Arenas A, Serrano C, Quiñones L, et al. High prevalence of clarithromycin resistance and effect on Helicobacter pylori eradication in a population from Santiago, Chile: cohort study and metaanalysis. Scientific Reports 2019;9:20070.

67. Yepes CA, Rodríguez A, Ruiz A, Ariza B. Resistencia antibiótica del Helicobacter pylori en el hospital universitario San Ignacio de Bogotá. Acta Médica Colombiana 2008;33:11-4.

68. Otth L, Wilson M, Fernández H, et al. Isolation of Helicobacter pylori in Gastric Mucosa and Susceptibility to Five Antimicrobial Drugs in Southern Chile. Braz J Microbiology 2011;42:442-7.

69. Ramírez-Bulla P, Mercado-Reyes M, Trespalacios-Rangel A, Ávila-Coy J, Otero-Regino W. Estado actual de la resistencia de Helicobacter pylori a tetraciclina: revisión sistemática de la literatura. www.javeriana.edu.co/ universitas_scientiarum 2012, Vol. $17 \mathrm{~N}^{\circ}$ 2:216-229.

70. Thiebaud L, Luque M, Sabillón L, Millares $\mathrm{H}$, Bustillo K. Eficacia del tratamiento convencional para Helicobacter pylori en niños. Rev Med Hondur 2011;79:65-67.

71. Ogata S, Ortiz A, Da Silva F, Kawakami E. High Helicobacter pylori Resistance to Metronidazole and Clarithromycin in Brazilian Children and Adolescents. J Pediatric Gastroenterol Nutr 2013;56:6458.

72. Mera Robertino, Bravo LE, Camargo MC, et al. Dynamics of Helicobacter pylori as a determinant of progression of gastric precancerous lesions: 16 -year follow-up of an eradication trial. Gut 2017;0:1-8.

73. Leal YA, Florez LL, Fuentes-Panama $\mathrm{EM}$, et al. $13 \mathrm{C}$ urea breath test for the diagnosis of Helicobacter pylori infection in children: a systematic review and metaanalysis. Helicobacter 2011;16:327-37.

74. Queiroz DM, Saito M, Rocha GA, et al. Helicobacter pylori infection in infants and toddlers in South America: concordance between [13C] urea breath test and monoclonal $H$. pylori stool antigen test. J Clin Microbiol 2013;51:3735-40.

75. Pacheco SL, Ogata SK, Machado RS, et al. Diagnosis of Helicobacter pylori infection By means of reduce-dose (13C) urea breath test and early sampling of exhaled breath. J Pediatric Gastroenterol Nutr 2013;57:607-11.

76. Zhou X, Su J, Xu G, et al. Accuracy of stool antigen test for the diagnosis of 
Helicobacter pylori infection in children: a meta-analysis. Clin Res Hepatol Gastroenterol 2014;38:629-38.

77. Raguza D, Machado RS, Ogata SK, et al. Validation of a monoclonal stool antigen for diagnosing Helicobacter pylori infection in young children. J Pediatr Gastroenterol Nutr. 2010;50:400-3.

78. De Carvalho Costa Cardinali L, Rocha G, et al. Evaluation of [13C] urea breath test and Helicobacter pylori stool antigen test for diagnosis of $H$. pylori infection in children from a developing country. J Clin Microbiol 2003;41:334-5.

79. Gatta L, Vakil N, Ricci C, et al. Effect of proton pump inhibitors and antacid Therapy on $13 \mathrm{C}$ urea breath test for Helicobacter pylori infection. Am J Gastroenterol 2004;99:823-9.

80. Horvath A, Dziechciarz P, Szajewska H. Meta-analysis: sequential therapy for Helicobacter pylori eradication in children. Aliment Pharmacol Ther. 2012;36:534-41.

81. Huang C-C, Tsai K-W, Tsai T-J, Hsu P-I. Update on the first-line treatment for Helicobacter pylori infection - a continuing challenge from an old enemy. Biomark Res. 2017;5:23.

82. Nyssen OP, McNicholl AG, Megraud F, et al. Sequential versus standard triple first-line therapy for Helicobacter pylori eradication. Cochrane Database Syst Rev. 2016 Jun 28;(6):CD009034. doi: 10.1002/14651858.CD009034.pub2.

83. Kwon YH, Kim N, Lee JY, et al. Comparison of the efficacy of culturebased tailored therapy for Helicobacter pylori eradication with that of the traditional second-line rescue therapy in Korean patients: a prospective single tertiary center study. Scand J Gastroenterol. 2016;51:270-6.

84. Ogata SK, Gales AC, Kawakami E. Antimicrobial susceptibility testing for Helicobacter pylori isolates from Brazilian children and adolescents: comparing agar dilution, E-test, and disk diffusion. Braz J Microbiol Publ Braz Soc Microbiol. 2014;45:1439-48.

85. Mahmoudi S, Mamishi S, Banar M, et al. Antibiotic susceptibility of Helicobacter pylori strains isolated from Iranian children: High frequency of A2143G point mutation associated with clarithromycin resistance. J Glob Antimicrob Resist. 2017;10:131-5.

86. Maleknejad S, Mojtahedi A, Safaei-Asl A, Taghavi Z, Kazemnejad E. Primary Antibiotic Resistance to Helicobacter pylori Strains Isolated From Children in Northern Iran: A Single Center Study. Iran J Pediatr. 2015;25(6):e2661. doi: 10.5812/ijp.2661.

87. Peretz A, Paritsky M, Nasser O, et al. Resistance of Helicobacter pylori to tetracycline, amoxicillin, clarithromycin and metronidazole in Israeli children and adults. J Antibiot (Tokyo). 2014;67:555-7.

88. Seo J-H, Jun J-S, Yeom JS, et al. Changing pattern of antibiotic resistance of Helicobacter pylori in children during 20 years in Jinju, South Korea: $H$. pylori and antibiotic resistance. Pediatr Int. 2013;55:332-6.

89. Ruíz-García E, Guadarrama-Orozco J, Vidal-Millán S, Lino-Silva LS, LópezCamarillo C, Astudillo-de la Vega H. Gastric cancer in Latin America, Scandinavian Journal of Gastroenterology 2018;53:124-9

90. International Agency for Research on Cancer. World Health Organization. Infection with Helicobacter pylori. In: Schistosomes, liver flukes and Helicobacter pylori. Lyon: IARC, 1994; 177-202.

91. Suzuki H, Mori H. World trends for H. pylori eradication therapy and gastric cancer prevention strategy by $\mathrm{H}$. pylori test-and-treat. J Gastroenterol. 2018;53:354-61.

92. Chang WL, Yeh YC, Sheu BS. The impacts of $H$. pylori virulence factors on the development of gastroduodenal diseases. J Biomed Sci. 2018;25:68.

93. Osaki T, Konno M, Yonezawa M, Hojo F, Zaman C, Takahashi M, Fujiwara S, Kamiya S. Analysis of intra-familial transmission of Helicobacter pylori in Japanese familias. Journal of Medical Microbiology 2015;64:67-73.

94. Weyermann M, Rothenbacher D, Brenner H. Acquisition of Helicobacter pylori infection in early childhood: independent contributions of infected mothers, fathers, and siblings. Am J Gastroenterol 2009;104:182-9.

95. Goodman KJ, Correa P. Transmission of Helicobacter pylori among siblings. Lancet 2000;355:358-62.

96. Mamishi S, Eshaghi H, Mahmoudi S, Bahador A, Hosseinpour Sadeghi R, Najafi M, Farahmand F, Khodadad A, Pourakbari B. Intrafamilial transmission of Helicobacter pylori: genotyping of faecal samples. Br J Biomed Sci. 2016;73:38-43.

97. de Brito BB, da Silva FAF, de Melo FF. Role of polymorphisms in genes that encode cytokines and Helicobacter pylori virulence factors in gastric carcinogenesis. World J Clin Oncol. 2018;9:83-9.

98. Chmiela M, Karwowska Z, Gonciarz W, Allushi B, St czek P. Host pathogen interactions in Helicobacter pylori related gastric cancer. World J Gastroenterol. 2017;23:1521-40.

99. Mommersteeg MC, Yu J, Peppelenbosch MP, Fuhler GM. Genetic host factors in Helicobacter pylori-induced carcinogenesis: Emerging new paradigms.
Biochim Biophys Acta Rev Cancer. 2018;1869:42-52.

100. Choi YJ, Kim N. Gastric cancer and family history. Korean J Intern Med. 2016;31:1042-53.

101. Yaghoobi M, McNabb-Baltar J, Bijarchi R, Hunt RH. What is the quantitative risk of gastric cancer in the first-degree relatives of patients? A meta-analysis. World J Gastroenterol. 2017;23:2435-42.

102. Cam S. Risk of Gastric Cancer in Children with Helicobacter pylori Infection. Asian Pac J Cancer Prev 2014;15:9905-8.

103. Ford AC, Forman D, Hunt RH, Yuan Y, Moayyedi P. Helicobacter pylori eradication therapy to prevent gastric cancer in healthy asymptomatic infected individuals: systematic review and metaanalysis of randomised controlled trials. BMJ. 2014;348:g3174. doi: 10.1136/bmj. g3174.

104. Ford AC, Forman D, Hunt R, Yuan Y, Moayyedi P. Helicobacter pylori eradication for the prevention of gastric neoplasia. Cochrane Database Syst Rev. 2015;(7):CD005583.

105. Yeh JM, Kuntz KM, Ezzati M, Goldie SJ. Exploring the cost-effectiveness of Helicobacter pylori screening to prevent gastric cancer in China in anticipation of clinical trial results. Int J Cancer. 2009;124:157-66.

106. Seta T, Takahashi Y, Noguchi Y, Shikata S, Sakai T, Sakai K, Yamashita Y, Nakayama T. Effectiveness of Helicobacter pylori eradication in the prevention of primary gastric cancer in healthy asymptomatic people: A systematic review and meta-analysis comparing risk ratio with risk difference. PLoS One. 2017;12(8):e0183321.

107. George S, Lucero Y, Torres JP, Lagomarcino AJ, O`Ryan M. Gastric Damage and Cancer-Associated Biomarkers in Helicobacter pylori-Infected Children. Front Microbiol. 2020 Feb 12;11:90. doi: 10.3389/fmicb.2020.00090. eCollection 2020

108. International Agency for Research on Cancer. Helicobacter pylori eradication as a strategy for preventing gastric cancer. Geneva, Switzerland: WHO Press, World Health Organization, 2014.

109. Sugano K, Tack J, Kuipers EJ, Graham DY, El-Omar EM, Miura S, Haruma K, Asaka M, Uemura N, Malfertheiner P. Kyoto global consensus report on Helicobacter pylori gastritis. Gut. 2015;64:1353-67.

110. Choi IJ, Kim CG, Lee JY, Kim YI, Kook MC, Park B, Joo J. Family history of gastric cancer and Helicobacter pylori treatment. N Engl J Med. 2020;382(5):427-36. doi: 10.1056/ NEJMoa 1909666. 